Article

\title{
Impacts on the Urban Environment: Land Cover Change Trajectories and Landscape Fragmentation in Post-War Western Area, Sierra Leone
}

\author{
Solomon Peter Gbanie ${ }^{1,2, *}$, Amy L. Griffin ${ }^{1,3}$ and Alec Thornton 1 (1) \\ 1 School of Physical, Environmental and Mathematical Sciences, University of New South Wales Canberra, \\ PO Box 7916, Campbell, ACT 2612, Australia; a.thornton@unsw.edu.au \\ 2 Geography Department, Faculty of Pure and Applied Sciences, Fourah Bay College, \\ University of Sierra Leone, Freetown 00232, Sierra Leone \\ 3 School of Science, RMIT University, GPO Box 2476, Melbourne, VIC 3001, Australia; amy.griffin@rmit.edu.au \\ * Correspondence: gbanie76@gmail.com; Tel.: +232-88-035-512
}

Received: 25 October 2017; Accepted: 5 January 2018; Published: 19 January 2018

\begin{abstract}
An influential underlying driver of human-induced landscape change is civil war and other forms of conflict that cause human displacement. Internally displaced persons (IDPs) increase environmental pressures at their destination locations while reducing them at their origins. This increased pressure presents an environment for increased land cover change (LCC) rates and landscape fragmentation. To test whether this hypothesis is correct, this research sought to understand LCC dynamics in the Western Area of Sierra Leone from 1976 to 2011, a period including pre-conflict, conflict, and post-conflict eras, using Landsat and SPOT satellite imagery. A trajectory analysis of classified images compared LCC trajectories before and during the war (1976-2000) with after the war (2003-2011). Over the 35-year period, the built-up land class rapidly increased, in parallel with an increase in urban and peri-urban agriculture. During the war, urban and peri-urban agriculture became a major livelihood activity for displaced rural residents to make the region food self-sufficient, especially when the war destabilised food production activities. The reluctance of IDPs to return to their rural homes after the war caused an increased demand for land driven by housing needs. Meanwhile, protected forest and other forest declined. A significant finding to emerge from this research is that landscape fragmentation increased in conjunction with declining forest cover while built-up areas aggregated. This has important implications for the region's flora, fauna, and human populations given that other research has shown that landscape fragmentation affects the landscape's ability to provide important ecosystem services.
\end{abstract}

Keywords: urban agriculture; land cover change trajectory; landscape fragmentation; landscape metrics; Sierra Leone; Western Area; Landsat

\section{Introduction}

Civil war and other forms of conflict that cause human displacement (hereinafter, conflict) are influential underlying drivers of human-induced landscape change [1-3]. Empirical geospatial research examining environmental impacts of human displacement resulting from conflict, especially when such displacement occurs within rather than across national boundaries, has increasingly identified significant environmental change in those environments. Several authors [4-7] have empirically demonstrated that internally displaced persons (IDP) crises are contributing to habitat and biodiversity loss, environmental degradation, and hydrological imbalances in areas where IDPs have relocated. These negative environmental consequences compromise the environment's potential to provide ecosystem services for the IDPs as well as to those who inhabited the area prior to 
the arrival of the IDPs, particularly during periods of protracted conflict [2,8]. Moreover, when IDPs cannot be accommodated within existing settlements, their introduction into a new landscape can lead to uncontrolled exploitation of forest resources and a concomitant increase in landscape fragmentation [3,9-11].

Yet, there is also evidence that conflicts sometimes help protect forest environments and their biodiversity, depending upon their nature and location [11,12]. For example, the demilitarized zone between North and South Korea has provided a "safe haven" for migratory birds [13]. Similarly, forests along the Thailand-Malaysia border, which remained untouched during periods of insurgency (1960-1970), have supported abundant wildlife and are being converted into a National Park by the Malaysian Government [14].

A principal driver of conflict-induced environmental changes, particularly at the urban-bush interface in communities that host IDPs, lies in the use of local natural resources to support IDP camp residents' livelihood activities and housing needs [15,16]. A study undertaken by Hagenlocher et al. [17] near an IDP camp in northern Darfur, Sudan, for example, concluded that a surge in population was accompanied by a decrease in area covered by shrubs, trees, and grass, and a marked expansion of small-scale farming plots. A second driver is the reluctance of IDPs to return to their rural homes after conflicts end [5]. Weak institutional frameworks within post-conflict societies (e.g., environmental policies, human resources, and lack of finance) and the desire by landless IDPs to own land in their new environments have been identified as contributing factors [11,18-21].

For several decades, research on the impacts of conflict on vegetation and biodiversity has largely measured land cover change (LCC) statistics, deforestation and urban expansion, and biodiversity loss [2,6]. Much of this research has focused on the amount of change rather than its spatial configuration. Yet, Mitchell et al. [22] maintain that information on landscape fragmentation is significant in any LCC research because levels of fragmentation often have significant effects on the capacity of a landscape to provide ecosystem services. A few studies have examined landscape fragmentation related to conflict [11,20]. IDP-settled areas in post-conflict Nicaragua along the Atlantic Coast were heavily fragmented because of population increases resulting from the conflict, especially in the north [11]. Nackoney et al. [20] concluded that core forest areas in the Democratic Republic of the Congo were more fragmented during the conflict but less fragmented in the post-conflict period. However, the opposite was the case for the peripheral forest, because the end of the conflict reduced pressure for resource extraction from the core forest.

In Sierra Leone, IDPs fleeing a civil war during the 1990s increased the population of the Western Area (WA). Despite the declaration of peace more than a decade ago, most IDPs have "stayed on" instead of returning to their former homes in the rural provinces. Some of the IDPs have stayed on in part due to the greater opportunities found in the WA that were absent in their rural homes (e.g., employment, health, and education). It is important to note that post-conflict environments are often fluid [23], marked by uncontrolled land access, and Sierra Leone provides an example of this situation $[7,24-26]$. Pressure from increased post-conflict development and reconstruction efforts has been identified as one factor contributing to the depletion of WA's forest resources, thereby having indirect negative effects on indigenous biodiversity and water resources [10,27]. Combined with Sierra Leone's weak environmental policies (e.g., fragmented responsibility for environmental decision-making among government ministries), which existed even before the conflict and persist today, development and reconstruction pressure and continued rural-urban migration are likely to lead to increased LCC and fragmentation rates [18]. Thus, we hypothesise that one would expect to find increased landscape fragmentation and a faster rate of LCC in the post-conflict period when compared with periods before and during the war.

To test whether the hypothesis is correct, this research sought to understand the pre- and post-conflict LCC dynamics in the WA between 1976 and 2011 using Landsat and SPOT satellite imagery. This research goes beyond the existing post-conflict LCC studies' focus on bi-temporal change detection and biodiversity loss $[2,6,7,19,20,28,29]$ by focusing on LCC trajectories and landscape 
fragmentation. The use of satellite images to assess the pattern of LCC trajectories and fragmentation trends provides empirical evidence on the nature and extent of environmental change over the study period for the WA, which is important for data-poor governments making land use planning and natural resource management decisions.

\section{Land Cover Change Assessment}

A commonly used technique for LCC assessment is the bi-temporal change detection technique [30,31]. The bi-temporal approach characterises landscape change by calculating the annual rate of change between two periods. When more than two periods are of interest, researchers employ trajectory techniques to reconstruct the pathway of historical LCCs using a series of satellite images [31-33]. Trajectory approaches can identify LCCs by type, magnitude, and the potential threats to various land cover classes in each landscape [34]. Given that neither bi-temporal nor trajectory analyses provide data about landscape configuration, when investigating the scale and magnitude of landscape change and its ecological impacts, fragmentation analysis may be helpful [35].

\subsection{Land Cover Change Trajectory}

A LCC trajectory is the temporal transition and sequence of land cover classes for a given location for more than two temporal observations [31,33]. For demonstration purposes, a trajectory of forest $\rightarrow$ agriculture $\rightarrow$ urban is a sequence in which a forested landscape became an agricultural field and then later became an urban area. Transition processes and sequences of change can be reconstructed using historical remotely sensed images; an advantage that traditional in situ observation does not offer [36]. This advantage, coupled with the difficulty in accessing conflict-affected areas to undertake in situ assessment of the landscape during a conflict, and post-war challenges in conducting fieldwork (e.g., financial and human resources), makes remote sensing appropriate for reconstructing historical land cover patterns.

\subsection{Landscape Fragmentation}

Landscape fragmentation, a key focus of landscape ecology, is the disaggregation of continuous habitat into smaller, isolated patches. The degree of fragmentation has relationships with patch size and number, shape, connectivity, and index features [37-39]. Drivers of landscape fragmentation can include both natural and anthropogenic forces, including civil war and other forms of conflict, landslides, and fire $[3,40,41]$. The resulting, small, isolated patches decrease both the aesthetic value and habitat quality of a landscape, which may lead to biodiversity loss and the establishment of invasive species in the landscape $[42,43]$. Despite these negative impacts of fragmentation, one positive impact is biomass production. Mitchell et al. [22] state that the effects of changing landscape structure or heterogeneity are also likely to be scale-dependent.

Landscape fragmentation research is typically operationalised through the use of fragmentation metrics at three scales: patch, class, and landscape [39]. A patch is a homogenous area of habitat and a class is a collection of patches of the same type. A collection of classes makes up the landscape. Several studies have explored fragmentation at these scales [22,39,44-46]. Exploring the relationship between LULCC, the drivers of change, and the ecological implications of such changes, Kabba and $\mathrm{Li}$ [45] concluded that fragmentation at the class and landscape scales in Wuhan, China was greatest in 1987-1994 but weakened in 1994-2005, leading first to species loss in the fragmented areas followed by a return of species as fragmented habitat areas re-aggregated. Analysis of fragmentation metrics (class and landscape scale) in the Weigou River Basin on the Chinese Loess Plateau showed increases in landscape heterogeneity and decreases in agricultural patch dominance [46]. Research by Fava et al. [47] demonstrated that ecological processes interact with patterns of LCC and fragmentation, and thereby have implications for the success of restoration initiatives in forested areas. For example, recruitment can affect whether a given strategy, such as passive management, leads to decreases in fragmentation and increases in patch connectivity. These studies are useful in demonstrating how 
fragmentation metrics can provide additional information about landscape change, information that is otherwise lacking when typical bi-temporal and trajectory analyses are conducted.

Our research analysed fragmentation at the class and landscape scales to provide an understanding of the intensity of landscape disturbance throughout the study period. This additional information can support a shift from responsive planning to intentional environmental design, especially in and near densely populated urban environments. Such data can be very useful in identifying areas that are at risk of change and therefore provide the basis, for example, in the case of fragmenting urban agriculture patches, for livelihood loss mitigation activities and action plans.

\section{Research Site}

On Sierra Leone's west coast, the WA $\left(557 \mathrm{~km}^{2}\right)$ is home to Freetown, the country's capital and largest city (Figure 1). Its climate is tropical with two seasons: the wet season from May-October, characterised by monsoonal rains and thunderstorms, followed by the dry season from November-April, with extreme temperatures in March [48]. The forest covering the Freetown Peninsula Mountain, the Western Area Peninsula Forest (WAPFoR), is part of the Upper Guinea Forest and is one of eight biodiversity hotspots in the country. This landscape is tentatively listed as a World Heritage site.

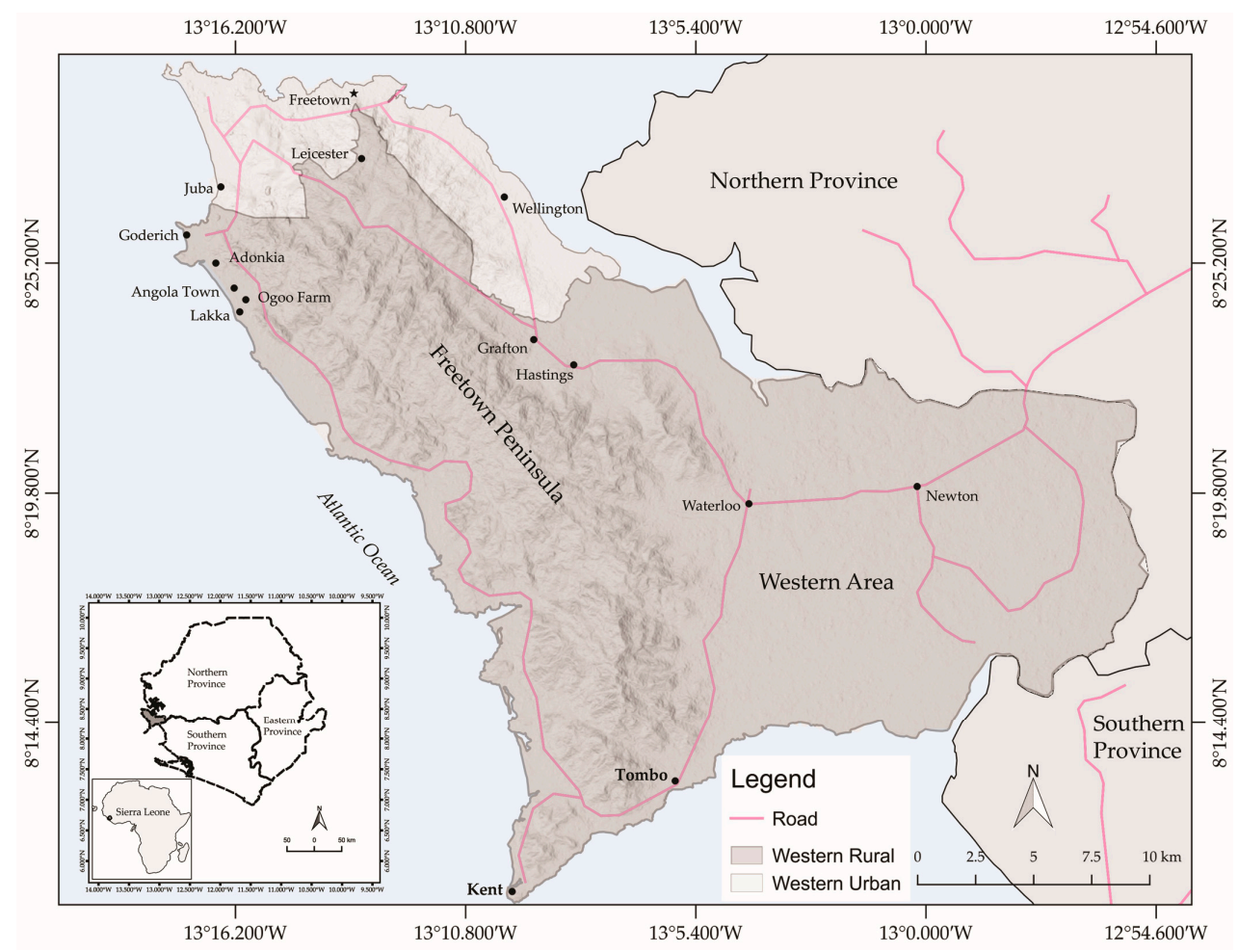

Figure 1. Location of study area and Sierra Leone (inset).

Half of Sierra Leone's 4.5 million people were displaced during the civil war (1991-2002), which helped almost double WA's population from 554,244 in 1985 to 947,112 in 2004 (Koroma et al. 2006; McGoldrick, 2003). The 2015 census figure for the WA was 1,493,252 people (442,951 for the Western Area Rural District Council and 1,050,301 for the Western Area Urban District) [49]. Following the abandonment of agricultural fields in rural areas, fleeing IDPs with agricultural skills arriving in the WA embarked on urban and peri-urban agriculture (UPA) [26,50,51]. UPA as defined here includes activities related to food production within or at the edges of urban areas and that provide sustenance for urban dwellers [51]. Its practice was underpinned by a combination of an embargo on the junta regime in 1997 and the "cut-off" of Freetown from its food supply catchment during the war. Other land 
use practices have also caused widespread degradation within the WAPFoR. These include wood harvesting by IDPs needing firewood and building materials, and house construction by urban elites seeking less crowded living environments [10]. These practices have rapidly pushed the city's limits into the Freetown Peninsula Mountain. Whilst earlier work by several authors attempted to examine the effect of population growth on the landscape by examining periods before and after the war, they relied upon bitemporal change detection rather than trajectory analysis [5,7,9]. Additionally, nothing is known about the level of landscape fragmentation at both the landscape and land cover class scales. This therefore indicates a need to undertake trajectory analysis and quantify the magnitude of landscape fragmentation at both the landscape and class scales.

\section{Materials and Methods}

\subsection{Remote Sensing Data}

Five Landsat images obtained from the GLOVIS website [52] and one SPOT image provided by Welthungerhilfe (WHH) (Table 1) were chosen for historical and recent landscape change analysis because of Landsat's long temporal record. The spatial resolution of these images makes it possible to identify and map agricultural fields, deforested areas, vegetated zones (old growth and reforested areas), and inhabited places within the landscape. The need for $100 \%$ cloud-free and near-date satellite images limited the selected images to the mid-dry season (January-March). In addition to a reduction in phenological effects within the various land cover classes during the dry season, important landscape change activities (land clearing/deforestation, agricultural activities and house construction) occur predominantly during this time of the year.

Table 1. Satellite images and their characteristics.

\begin{tabular}{ccccc}
\hline Date & Satellite \& Sensor & No of Bands & Spatial Resolution $(\mathbf{m})$ & Periods \\
\hline $02-03-76$ & Landsat 2 (MSS) & 4 & 60 & Before the war \\
$19-01-86$ & Landsat 5 (TM) & $7^{\alpha}$ & $30\left(60^{* *}\right)$ & During the war \\
$03-02-00$ & Landsat 7 (ETM $\left.{ }^{+}\right)$ & $8^{\beta}$ & $30\left(15^{*} \& 60^{*}\right)$ & \\
$27-02-03$ & Landsat 7 (ETM) & $8^{\beta}$ & $30\left(15^{*} \& 60^{* *}\right)$ & After the war \\
$10-03-06$ & SPOT 5 & $7^{* *}$ & $30\left(60^{* *}\right)$ & \\
$09-02-11$ & Landsat 5 (TM) & $7^{\beta}$ & & \\
\hline
\end{tabular}

${ }^{\alpha}$ All bands used except the thermal band (Band 6); ${ }^{\beta}$ All bands used except the thermal and panchromatic bands (band 6 and 8 ); ${ }^{*}$ Resolution of the panchromatic band; ${ }^{* *}$ Resolution of the thermal band; *** Image was already stacked.

\subsection{Ground Truthing Data}

Ground truthing exercises between December 2012 and January 2013 used a GPS receiver to generate data for classification training and land cover classification accuracy assessments for the 2011 image. The field data collection exercise was undertaken to ascertain the accuracy and reliability of the assigned land cover classes during image classification. Accuracy assessment of other image dates used the available corresponding or near corresponding ancillary data from Landsat Google Earth Pro images (1976, 1986 \& 2003) and high-resolution aerial photographs (2000 \& 2007). One hundred and thirty samples for each land cover class were used for the accuracy assessment, a total of 910 ground truth points for each of the images except the 1976 image where 780 points were used because UPA was not identifiable.

\subsection{Image Pre-Processing and Classification}

Figure 2 outlines the 4-step methodological framework adopted in analysing historical and recent landscape change. Whilst no georeferencing was required because all of the images were already properly aligned, the "georeferencing image mosaicking" technique was used to mosaic the two 2006 SPOT image scenes together. All satellite images except the SPOT image (already 
corrected by $\mathrm{WHH}$ ) were radiometrically corrected using the Improved Dark Object Subtraction (IDOS) algorithm, removing unwanted materials, including noise and sensor errors [30]. Unlike the Apparent Reflection and the Dark Object Subtraction methods, IDOS accounts for the atmospheric multiplicative transmission component of the image at two stages [53]. First, utilising the maximum and minimum spectral radiance relationships, digital numbers were converted to at-sensor spectral radiance values. Second, to reduce the scene-to-scene image variability, radiance values were converted to surface reflectance [54]. Upscaling and downscaling techniques using nearest neighbour resampling were applied to the original images to match the spatial resolution of SPOT and MSS images to the TM and ETM+ images $(30 \mathrm{~m})$ since they constituted the majority of the images [46].

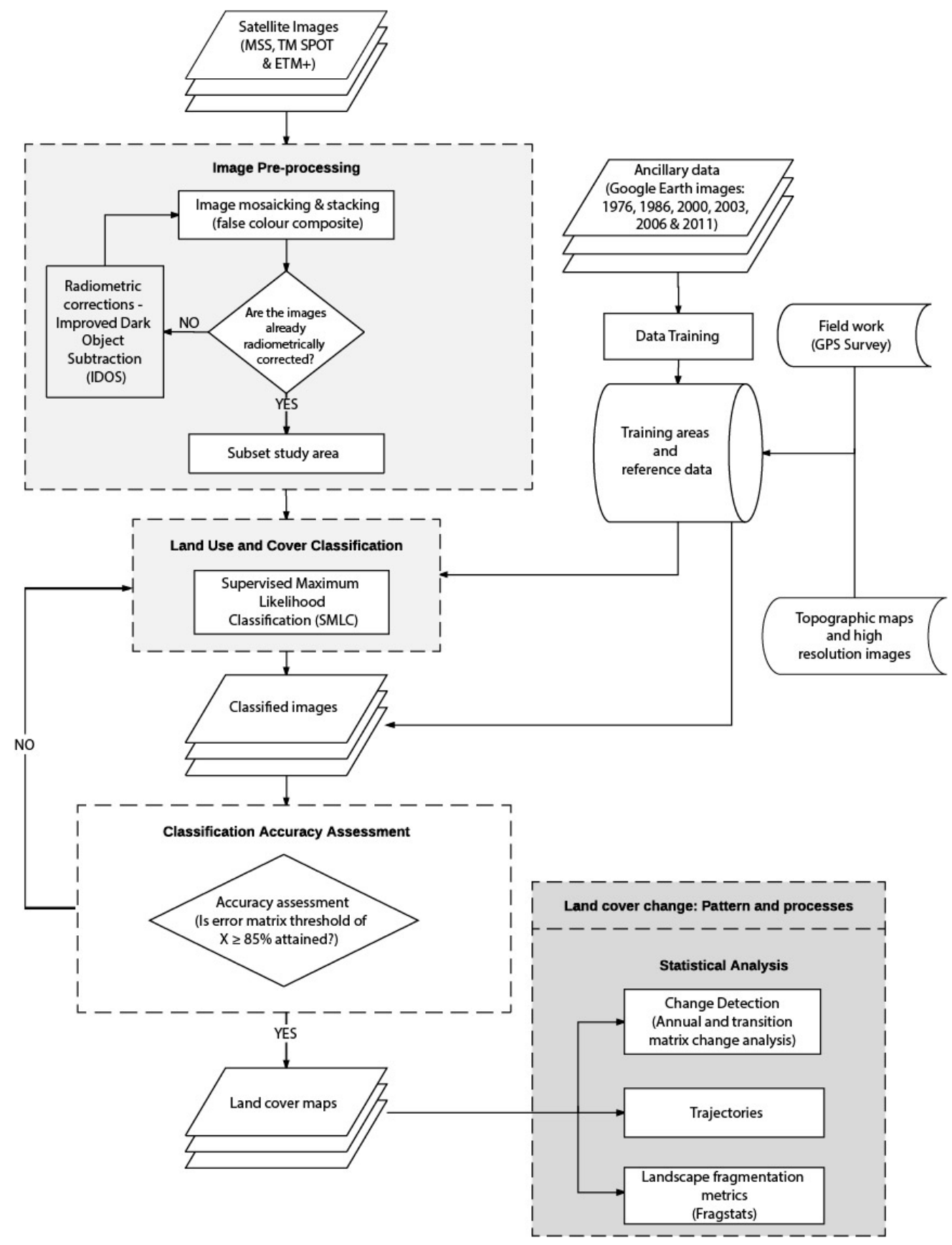

Figure 2. Research methodology flowchart. 
Following radiometric correction, all of the images except the 1976 image were classified into seven land cover classes (Table 2) using a pixel-based, supervised maximum likelihood classification (SMLC) algorithm. Although some recent LULCC research has employed machine learning algorithms to classify satellite images, we used SLMC because it has been successfully applied in studies conducted in comparable environments using similar data [37].

Table 2. Land cover classes.

\begin{tabular}{cl}
\hline Class & \multicolumn{1}{c}{ Description } \\
\hline Built-up & Residential, industrial, and commercial structures and motorways \\
Bare land & Unvegetated land, exposed rocks, and burnt out areas \\
Other forest & Areas with woody vegetation that are neither protected forest nor mangroves \\
Mangrove & Shrubs found on the coastal tidal flats \\
Protected forest & Reserved and protected forest \\
Urban \& peri-urban agriculture & Vegetable gardens and other cropland areas \\
Waterbody & Streams, rivers, ponds, and reservoirs \\
\hline
\end{tabular}

The 1976 satellite image was classified into six land cover classes (Built-up, Protected forest, Other forest, Bare land, Waterbody and Mangrove). Despite resampling the image to $30 \mathrm{~m}$, the seventh land cover class, urban and peri-urban agriculture (UPA), was not easily distinguishable in the 1976 image because of the relatively small spatial extent of urban and peri-urban agricultural fields within the image and the spectral similarities with land cover classes that were nearby.

The land cover classes, adapted from Anderson's Level 1 Land Cover Classification Scheme, were chosen because the spatial resolution for all the images but one was relatively coarse. The adoption of Anderson's Level 1 classification scheme made it possible to identify human-induced landscape change activities including UPA, deforestation, and housing construction, but impossible to undertake level 2 or 3 classification [see [55] for details on levels 1, 2 \& 3 land cover classification schemes]. A protected forest class enabled us to distinguish between forests with old growth structure and forests that have been disturbed by human activities. Protected areas are protected both through their (relative) inaccessibility as well as their legal demarcation as protected (This protected demarcation was originally declared in 1916 but the lands were first actually gazetted as protected in 1973. A revised, demarcated boundary was approved in 2011, and by 2012, it was renamed the Western Area Peninsula National Park (see [56])). The six classified satellite images were assessed for accuracy of the assigned land cover classes against the ground truth and ancillary data. An accuracy assessment conducted using an error matrix approach (confusion matrices) generated producer's and user's accuracies, including omission and commission errors (see accuracy assessment results, Table 3). Statistical and GIS analysis of classified images, including change detection, constructing LCC trajectories, and calculating landscape fragmentation metrics, described in the following sections, revealed the nature and level of historical and recent changes in the study area's landscape.

Table 3. Accuracy assessment.

\begin{tabular}{|c|c|c|c|c|c|c|c|c|c|c|}
\hline Year & $\begin{array}{c}\text { Overall } \\
\text { Accuracy }\end{array}$ & $\begin{array}{c}\text { Kappa } \\
\text { Coefficient }\end{array}$ & $\begin{array}{c}\text { Type of } \\
\text { Accuracy }\end{array}$ & Built-Up & $\begin{array}{l}\text { Protected } \\
\text { Forest }\end{array}$ & $\begin{array}{l}\text { Other } \\
\text { Forest }\end{array}$ & $\begin{array}{l}\text { Bare } \\
\text { Land }\end{array}$ & Waterbody & Mangrove & UPA \\
\hline \multirow{2}{*}{1976} & \multirow{2}{*}{$91.0 \%$} & \multirow{2}{*}{0.88} & PA & 91.6 & 98.1 & 92.1 & 89.3 & 100.0 & 82.5 & - \\
\hline & & & UA & 99.5 & 89.55 & 90.74 & 75.3 & 72.2 & 96.6 & - \\
\hline \multirow{2}{*}{1986} & \multirow{2}{*}{$90.3 \%$} & \multirow{2}{*}{0.88} & PA & 95.8 & 80.40 & 93.27 & 96.0 & 100.0 & 96.53 & 52.8 \\
\hline & & & UA & 96.3 & 98.95 & 81.51 & 87.1 & 100.0 & 89.86 & 66.7 \\
\hline \multirow[b]{2}{*}{2000} & \multirow{2}{*}{$91.8 \%$} & \multirow[b]{2}{*}{0.90} & PA & 97.7 & 100.0 & 81.29 & 100.0 & 91.56 & 95.33 & 78.1 \\
\hline & & & UA & 100.0 & 73.33 & 93.56 & 80.7 & 100.0 & 99.3 & 98.2 \\
\hline \multirow[b]{2}{*}{2003} & \multirow{2}{*}{$93.1 \%$} & \multirow[b]{2}{*}{0.91} & PA & 99.7 & 99.6 & 98.6 & 85.9 & 100.0 & 81.6 & 78.6 \\
\hline & & & UA & 100.0 & 96.1 & 68.79 & 84.3 & 82.1 & 96.9 & 94.7 \\
\hline \multirow{2}{*}{2006} & \multirow{2}{*}{$87.8 \%$} & \multirow{2}{*}{0.85} & PA & 89.82 & 83.81 & 91.67 & 98.7 & 100.0 & 96.5 & 55.6 \\
\hline & & & UA & 97.45 & 98.33 & 79.89 & 82.8 & 100.0 & 90.3 & 57.1 \\
\hline \multirow{2}{*}{2011} & \multirow{2}{*}{$96.5 \%$} & \multirow{2}{*}{0.96} & PA & 98.96 & 100.0 & 96.24 & 97.88 & 100.0 & 82.33 & 98.31 \\
\hline & & & UA & 99.53 & 93.23 & 94.34 & 99.38 & 100.0 & 98.73 & 92.06 \\
\hline
\end{tabular}




\subsection{Change Detection: Annual and Transitional Changes}

Considerable discussion comparing different change detection techniques exists [57,58]. In this research, post-classification use of the compound interest derivative Equation (1) [59] provided an overview of the magnitude of landscape change by computing the annual percentage rates of LCC for each class. Post-classification change detection is advantageous since it provides 'from and to' LCC matrix statistics.

$$
\Delta \mathrm{r}=\left(\left(\ln \mathrm{Y}_{2}-\ln \mathrm{Y}_{1}\right)(\mathrm{t} 2-\mathrm{t} 1)^{-1}\right) \times 100
$$

In Equation (1), $\Delta \mathrm{r}$ represents the percentage annual rate of change for each land cover class and $\ln Y_{1}$ and $\ln Y_{2}$ are the natural logarithm of the areal extent of each LCC class for $t_{1}$ and $t_{2}$, respectively; $\Delta \mathrm{t}$ is the time interval (note that $\mathrm{t}_{2}$ and $\mathrm{t}_{1}$ are in years).

LCC transition matrices (1976-1986, 1986-2000, 2000-2003, 2003-2006, 2006-2011 and 1976-2011) were computed using ArcGIS 10.2. In this research, the term transition matrix means a two-dimensional computation of pixels that changed from one class to another between an earlier $\left(\mathrm{T}_{1}\right)$ and later $\left(\mathrm{T}_{2}\right)$ year. Protected forest, other forest and mangrove land cover classes were further generalised into one super-class; "woody vegetation". We have abbreviated this to "vegetation" to provide a less wordy label in the figures. This generalisation allowed a more conceptually concise identification of landscape change processes in the transition matrices. The transition matrices were generalised into nine clusters representing different change processes (no change, abandonment, afforestation, cultivation, deforestation, degradation, recession, tidal waters and urbanisation). Row-wise and column-wise matrix analysis of the nine change processes identified the percentage of change between classes (see the matrix and Equations (2)-(5)).

\begin{tabular}{c|cccc|c}
$i / j$ & $C_{1}$ & $C_{2}$ & $\ldots$ & $C_{j}$ & \\
\hline$R_{1}$ & $U_{11}$ & $U_{12}$ & $\ldots$ & $U_{1 j}$ & $\sum R_{1}$ \\
$R_{2}$ & $U_{21}$ & $U_{22}$ & $\ldots$ & $U_{2 j}$ & $\sum R_{2}$ \\
$\cdot$ & $\cdot$ & $\cdot$ &. & $\cdot$ & $\cdot$ \\
$\cdot$ & $\cdot$ & $\cdot$ &. & $\cdot$ & $\cdot$ \\
$\cdot$ & $\cdot$ &. &. &. & $\cdot$ \\
$R_{i}$ & $U_{i 1}$ & $U_{i 2}$ & $\ldots$ & $U_{i j}$ & $\sum R_{i}$ \\
\hline & $\sum C_{1}$ & $\sum C_{2}$ & $\ldots$ & $\sum C_{j}$ & $\sum C R_{i j}$
\end{tabular}

$$
\begin{gathered}
P_{i j}=\left\{\frac{U_{i j}}{\sum C_{i}}\right\} \times 100 \\
Q_{i j}=\left\{\frac{U_{i j}}{\sum R_{i}}\right\} \times 100 \\
\alpha_{i j}=\left\{1-\frac{U_{i j}}{\sum C_{i}}\right\} \times 100 \\
\beta_{i j}=\left\{1-\frac{U_{i j}}{\sum R_{i}}\right\} \times 100
\end{gathered}
$$

where:

$P_{i j}=$ Percentage area of a given class in $T_{1}$ that changed away from that class in $T_{2}$

$Q_{i j}=$ Percentage area of a given class in $T_{1}$ that changed into another class in $T_{2}$

$\mathrm{U}_{\mathrm{ij}}=$ Areal extent of a land use class at times $i$ and $j$

$\alpha_{i j}=$ Total percentage of change from any other class in $T_{1}$ to a given class in $T_{2}$ 
$\beta_{\mathrm{ij}}=$ Total percentage of change from one land class in $\mathrm{T}_{1}$ to any other class in $\mathrm{T}_{2}$

$\sum C_{\mathrm{ij}}=$ Column total

$\sum \mathrm{R}_{\mathrm{ij}}=$ Row total.

\subsection{Trajectory Analysis}

Trajectory analysis was undertaken using five land cover classes (built-up, bare land, woody vegetation, UPA and waterbody). The overall study period was split into two periods: before and during the war (1976-2000) and after the war (2003-2011), to enhance the comparison of LCC processes for the two time-frames (Figure 3).
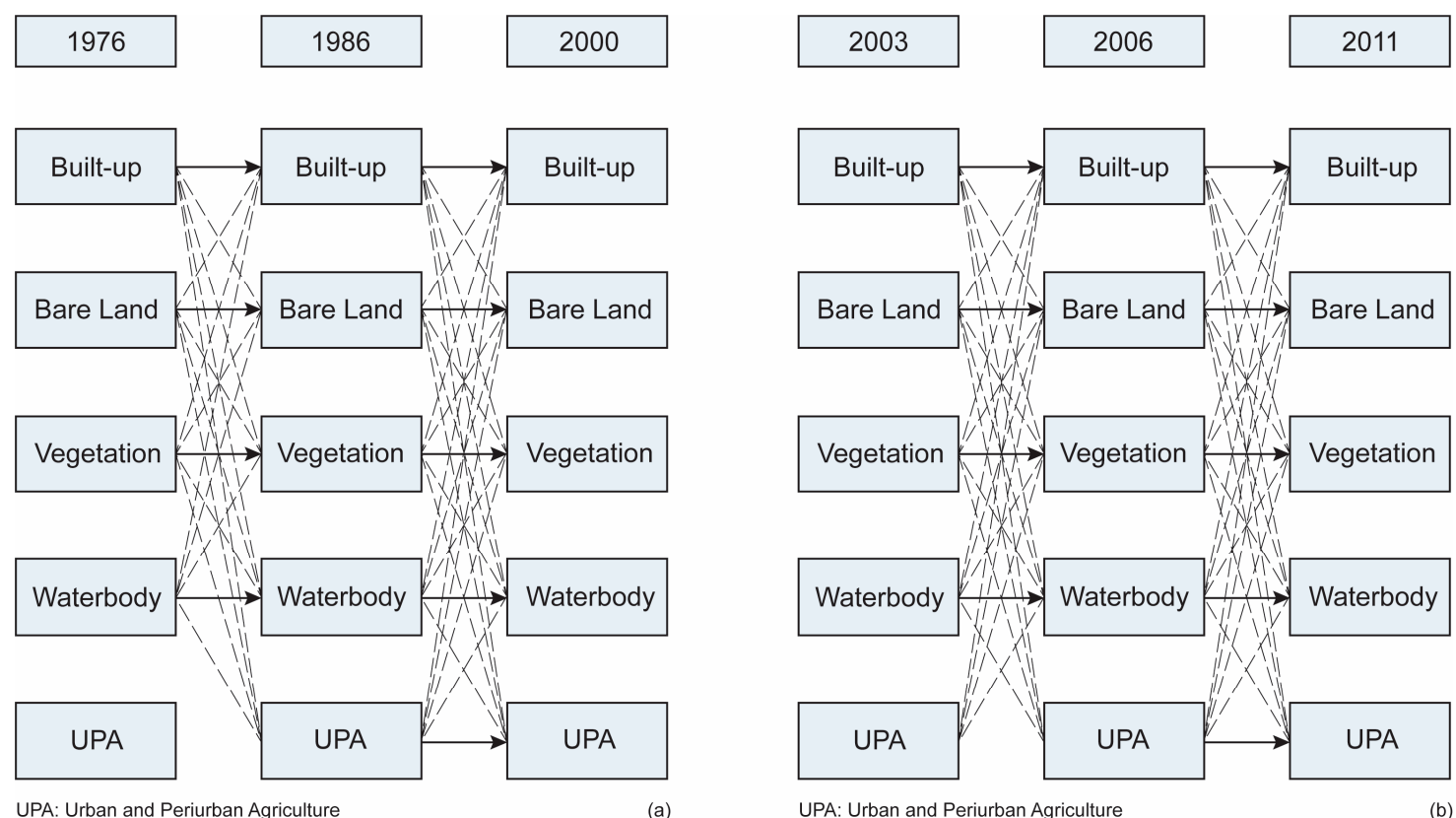

Figure 3. All possible land cover change trajectories: (a) before and during the war (1976-2000); (b) after the war (2003-2011). The 1976 image did not allow the identification of UPA because of its coarse spatial resolution. Nevertheless, this time point was included in the analysis to provide historical context for the region's landscape.

\subsection{Landscape Fragmentation Analysis}

Landscape metrics describing fragmentation levels at two scales (class and landscape) from the pre- to post-war periods were computed using FRAGSTATS 4.2 [60]. Using up- or down-scaled, multi-resolution LULC classifications can induce unwanted artefacts into a landscape fragmentation analysis. Therefore, we excluded the 1976 and 2006 images from this portion of the analysis. Earlier research recommends the use of fragmentation metrics that depict distinct and meaningful fragmentation features rather than utilising metrics that are statistically redundant $[3,41,44,61]$. Given the complex nature of landscape disaggregation into isolated patches, several scholars have argued that a single parameter is insufficient to describe the trend and magnitude of landscape disaggregation $[22,44,62]$. The selected metrics for this research satisfied two criteria: they measured different parameters of the landscape (i.e., are not statistically redundant) and they are known to have played a significant role in understanding landscape fragmentation from research using data sets similar to those used in this research [44,45]. The metrics we used include number of patches (NumP), percentage of landscape (PLAND), largest patches index (LPI), landscape shape index (LSI), interspersion and juxtaposition index (IJI), contagion index (CONTAG), and Simpson's and Shannon' Diversity Indices (SDI \& SHDI) [see 60 for definition and description of these metrics]. Performing 
landscape fragmentation analysis at these scales gave insight into the level of landscape disturbance for the two periods (before and during the war versus after the war) for the entire study area.

\section{Results}

\subsection{Accuracy Assessment}

Accuracy assessment using the conventional error matrix technique showed the image classification met the recommended 85\% accuracy threshold [55] for all images (range: 87.8-96.5\%) (Table 3). The 2006 land cover map had the lowest overall accuracy in comparison to the other years. Upscaling the 2006 SPOT image could be responsible for the lower accuracy result of the image. Despite the lower accuracy of the SPOT image in comparison to the other satellite images, it met the $85 \%$ accuracy threshold [55]. The least accurate class in the classified SPOT image is UPA, likely due to mixed pixel effects induced by the upscaling. The producer's accuracy figures show that the UPA class in the 1986 image is the least accurately classified land cover class across any image. The low producer's accuracy for the UPA land cover class suggests misclassification of pixels that probably belong to mangrove and built-up land cover classes due to their proximity and mixed-pixel effects. Therefore, information about the UPA class in that year must be treated with caution.

\subsection{Land Cover Change Patterns (1976-2011)}

The graphs (Figure 4) illustrate the fraction of the study area occupied by each land cover class and the maps (Figure 5) show the spatial distribution of each land cover over the 35-year study period for the WA. Built-up areas increased remarkably but forests declined, except for protected forest from 1976-1986 (Figure 4). There was substantial expansion of UPA in 2000, which persisted during the post-war years. Of note are the increases in built-up areas along the Juba-Ogoo Farm and Wellington-Waterloo axes, in the west and east of WA, respectively, making the rural-urban divide less distinct (Figure 6).

Built-up areas showed a yearly gain of $9.2 \%$ and bare land gained approximately $7 \%$ in 2000 and $9.5 \%$ in 2003 , the highest for the 35-year study period. The highest annual decline in other forest $(3.3 \%)$ occurred between 2000 and 2003. That of protected forest, nearly 3\%, occurred between 2003 and 2006. The relative stability of mangrove vegetation, comprising about $10 \%$ of the study area over most of the study period, can be explained by the inaccessibility of some of the areas where the mangroves exist. Many mangroves are in water-logged areas that are relatively inaccessible and are, for the most part, far from populated areas. The highest annual gain in UPA, about 3.3\%, occurred between 1986 and 2000. Given that UPA was unidentifiable on the 1976 Landsat image, it caused declines in some other land classes that are not true changes (pixels that could not actually be classified as UPA in 1976). 
(a) Built up

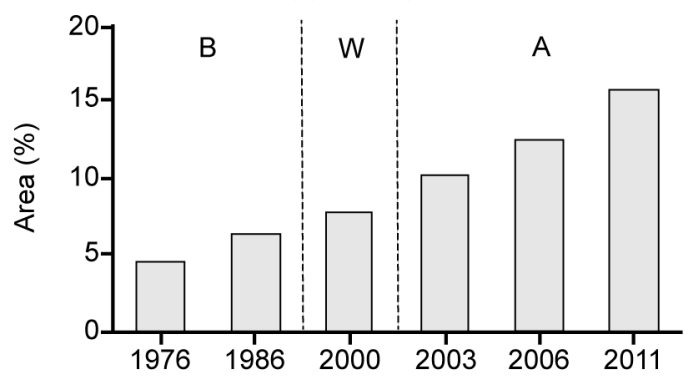

(c) Protected forest

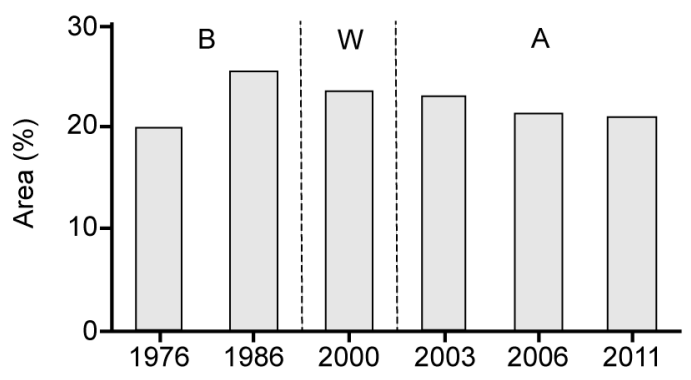

(e) Other forest

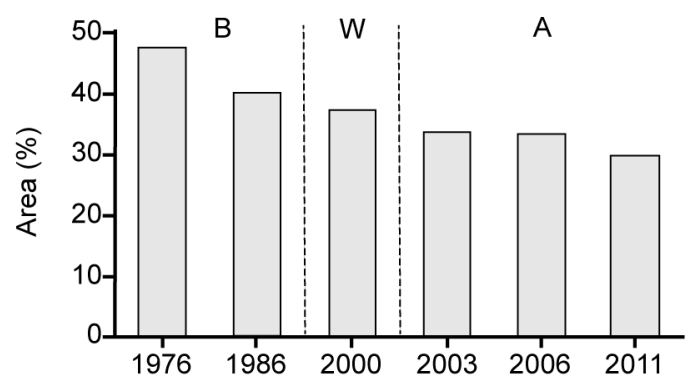

(g) Bare land

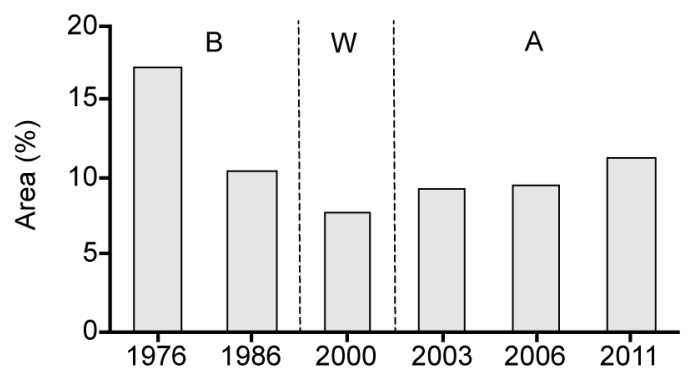

(b) Waterbody

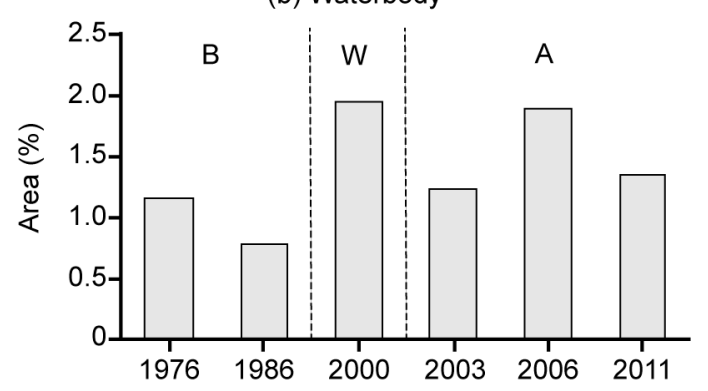

(d) Mangrove

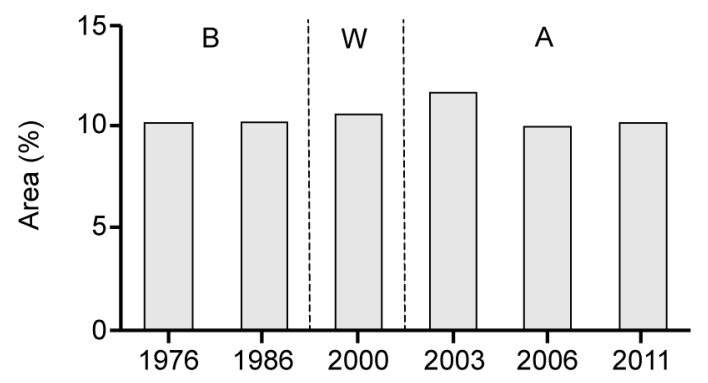

(f) Urban and periurban agriculture (UPA)

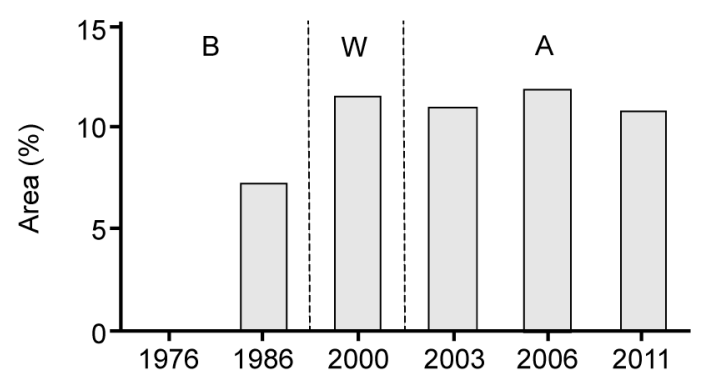

Figure 4. Graphs illustrating the proportion of each land cover class over the study period: (a) built up; (b) waterbody; (c) protected forest; (d) mangrove; (e) other forest; (f) urban and periurban agriculture; (g) bare land.
B: Before the war
W: During the war
A: After the war 

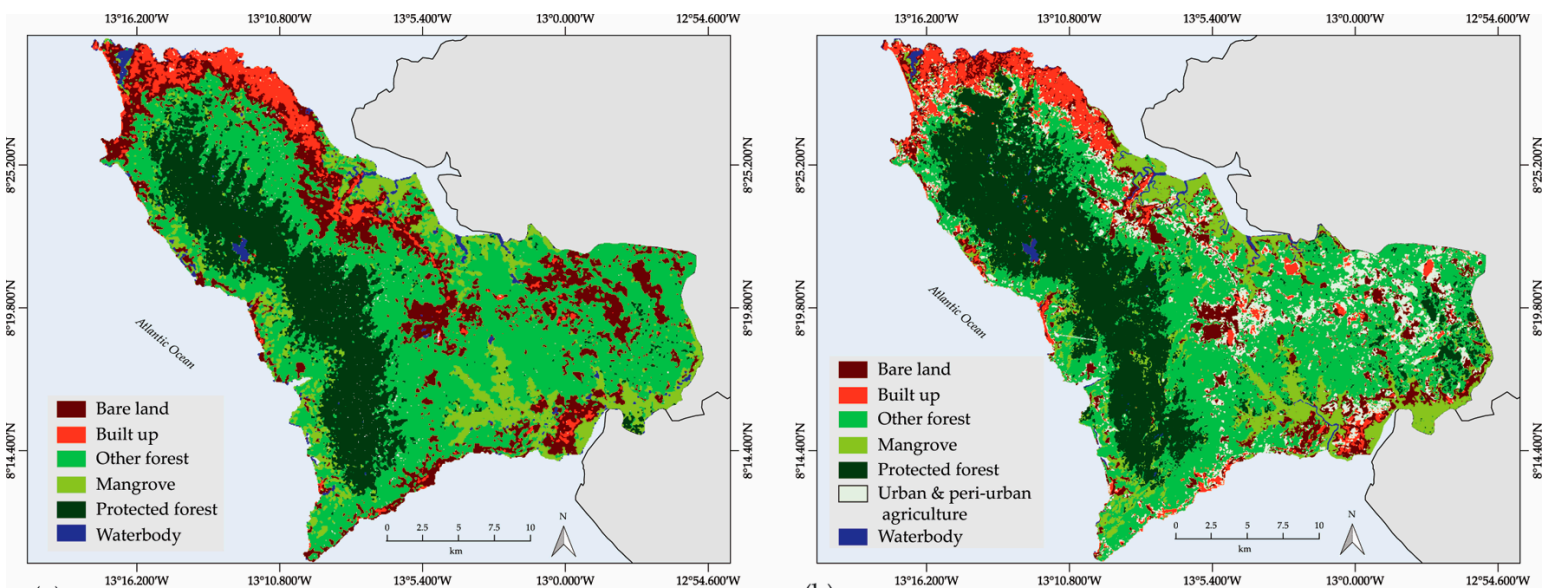

(a)

(b)
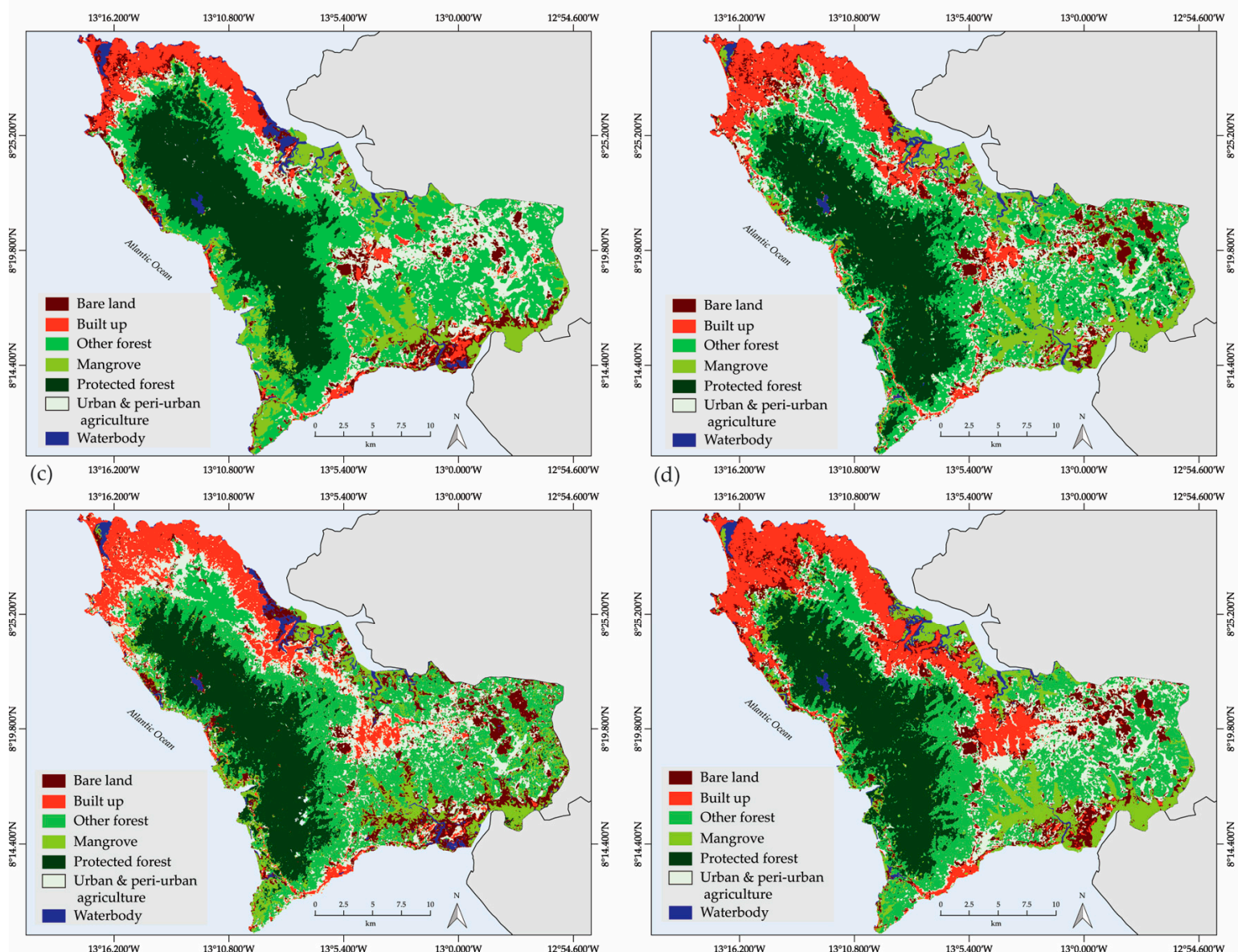

(e)

(f)

Figure 5. Land cover in the Western Area for the years studied: (a) 1976; (b) 1986; (c) 2000; (d) 2003; (e) 2006; and (f) 2011. 


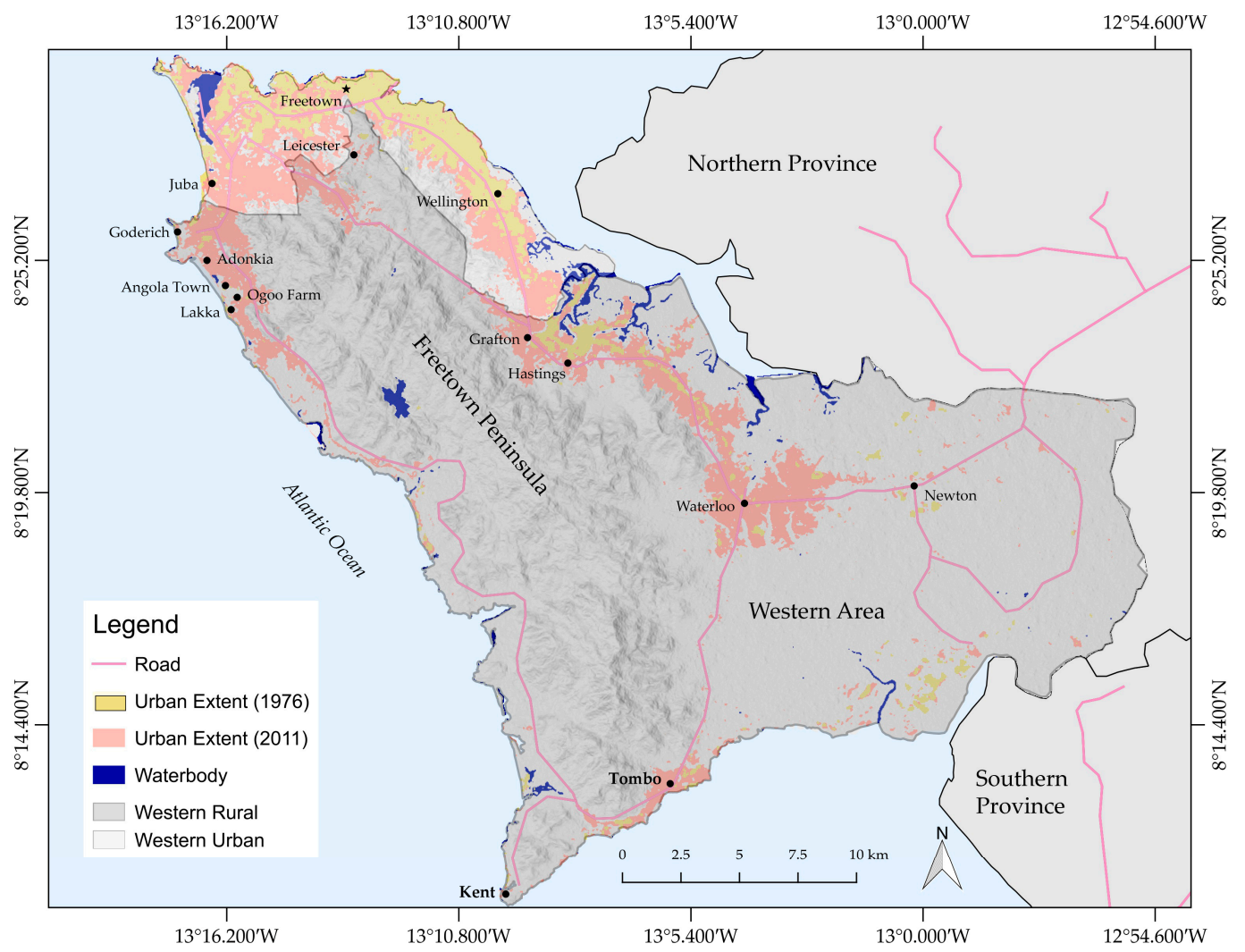

Figure 6. Urban extent in 1976 and 2011.

\subsection{Land Cover Change Trajectory Analysis}

LCC trajectory analysis demonstrated both the magnitude and type of land cover changes. Post-conflict LCC trajectory analysis, which investigated the period of post-conflict rebuilding efforts, helped in identifying the most frequently changing land cover classes. In 2011 , almost $59 \%$ of bare land, $62 \%$ of UPA, and 31\% of built-up areas were other land covers in 2006 (Table 4). During the same period, nearly $66 \%$ of UPA, $51 \%$ of bare land, and $44 \%$ of waterbody was lost to other land covers. In the immediate post-conflict transition (2000-2003), 62.3\% of UPA in 2006 came from other land cover classes in 2003 and $64 \%$ of bare land in 2003 was another land cover class in 2000 (Table 4). Several noticeable land cover transitions occurred after the war. From 2000 to 2003, major land cover transitions included vegetation $\rightarrow$ UPA (55\%) and UPA $\rightarrow$ Bare land (38\%). Between 2003 and 2006, similar land cover transitions included Vegetation $\rightarrow$ Bare land $(47 \%)$ and Vegetation $\rightarrow$ UPA $(25 \%)$. Similarly, between 2006 and 2011, noticeable land cover transitions included vegetation $\rightarrow$ UPA (47\%), Vegetation $\rightarrow$ Bare land (26\%), UPA $\rightarrow$ Bare land (26\%) and UPA $\rightarrow$ Built-up (21\%) (Figure 7).

Table 4. Percentage of pixels associated with types of land cover change between observations.

\begin{tabular}{|c|c|c|c|c|c|c|c|c|c|c|}
\hline \multirow[b]{2}{*}{ Year } & \multicolumn{5}{|c|}{$\begin{array}{l}\text { Percentage of Pixels in } T_{2} \text { Classified as a Another } \\
\text { Class in } T_{1}\end{array}$} & \multicolumn{5}{|c|}{$\begin{array}{l}\text { Percentage of Pixels in } T_{1} \text { That Became Another } \\
\text { Class in } T_{2}\end{array}$} \\
\hline & Built-up & $\begin{array}{l}\text { Bare } \\
\text { land }\end{array}$ & $\begin{array}{c}\text { Woody } \\
\text { vegetation }\end{array}$ & Water & UPA & Built-up & $\begin{array}{l}\text { Bare } \\
\text { land }\end{array}$ & $\begin{array}{c}\text { Woody } \\
\text { vegetation }\end{array}$ & Water & UPA \\
\hline 1976-1986 & 49.1 & 46.3 & 6.6 & 37.4 & - & 30.4 & 67.3 & 9.0 & 57.0 & - \\
\hline 1986-2000 & 42.2 & 46.3 & 5.3 & 63.1 & 68.2 & 28.9 & 60.3 & 10.6 & 9.0 & 49.5 \\
\hline 2000-2003 & 35.3 & 64.9 & 7.8 & 12.9 & 62.2 & 13.8 & 57.9 & 11.5 & 43.2 & 64.0 \\
\hline 2003-2006 & 26.0 & 60.9 & 6.7 & 47.8 & 54.3 & 9.9 & 60 & 12.1 & 16.1 & 50.8 \\
\hline 2006-2011 & 30.7 & 58.9 & 8.1 & 15.8 & 62.1 & 12.9 & 51.2 & 12.7 & 43.6 & 65.6 \\
\hline 1976-2011 & 74.6 & 51.0 & 5.0 & 51.5 & - & 12.8 & 67.8 & 34.3 & 41.7 & - \\
\hline
\end{tabular}




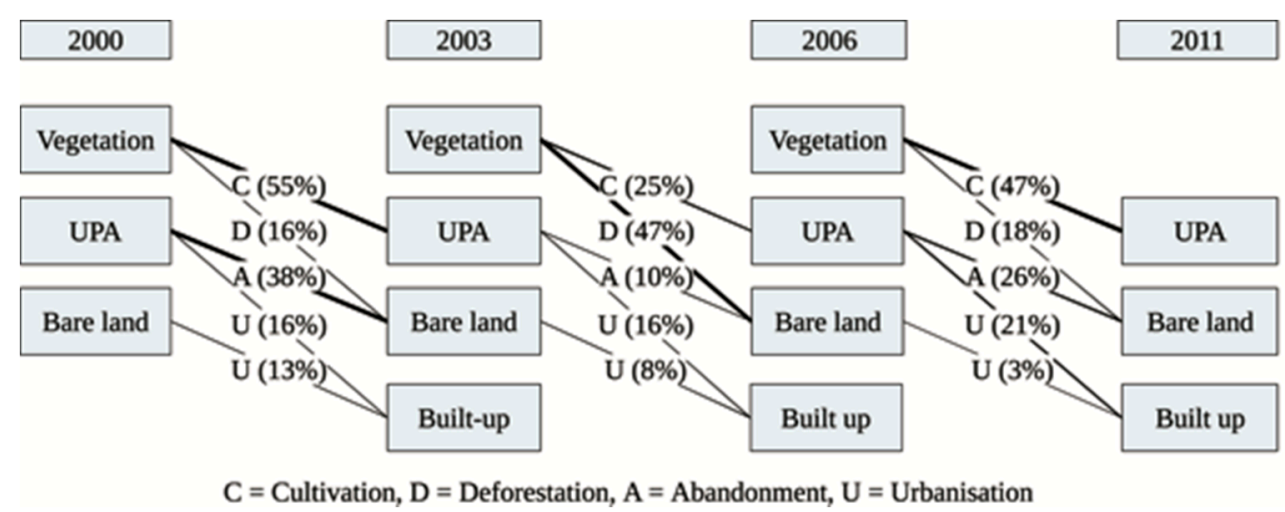

Figure 7. Major land cover transitions.

Throughout the study period, gains in the spatial extent of built-up areas were at the cost of UPA and bare land. Woody vegetation (this combines the two forest classes) lost mostly to UPA, bare land, and built-up areas. This is not surprising, because most urban development starts with the clearing of vegetation. Hence, it transitions to bare land before buildings are constructed. Whilst bare land awaits development, urban agriculturists often cultivate on these empty urban spaces.

LCC trajectories were categorised into eight change processes and a no-change class, which is shown in white (Figure 8). Before and during the war (1976-2000), trajectories for the no-change category included vegetation $\rightarrow$ vegetation $\rightarrow$ vegetation $(\mathrm{V} \rightarrow \mathrm{V} \rightarrow \mathrm{V}: 63.6 \%$; woody vegetation is abbreviated as V) and built-up $\rightarrow$ built-up $\rightarrow$ built-up ( $\rightarrow \mathrm{B} \rightarrow \mathrm{B}: 2.8 \%$ ) (Table 5). During the post-conflict period (2003-2011), a higher percentage of built-up areas was stable than in the earlier period $(\mathrm{B} \rightarrow \mathrm{B} \rightarrow \mathrm{B}: 8.5 \%)$, but woody vegetation was less stable $(\mathrm{V} \rightarrow \mathrm{V} \rightarrow \mathrm{V}: 54.2 \%)$. Agriculture $\rightarrow$ Agriculture $\rightarrow$ Agriculture $(\mathrm{A} \rightarrow \mathrm{A} \rightarrow \mathrm{A})$ was only analysed for the post-conflict period because UPA was not identifiable on the 1976 Landsat image due to its coarse spatial resolution. Cultivation, the transition of land from any other land cover to UPA, was more common before and during the war than after the war (11.5\% and $8.1 \%$, respectively). Urbanisation, abandonment, and degradation recorded moderate increases in the post-conflict period. Figure $8 \mathrm{c}$ shows that post-conflict urbanisation occurred mostly along the Waterloo-Wellington axis. 

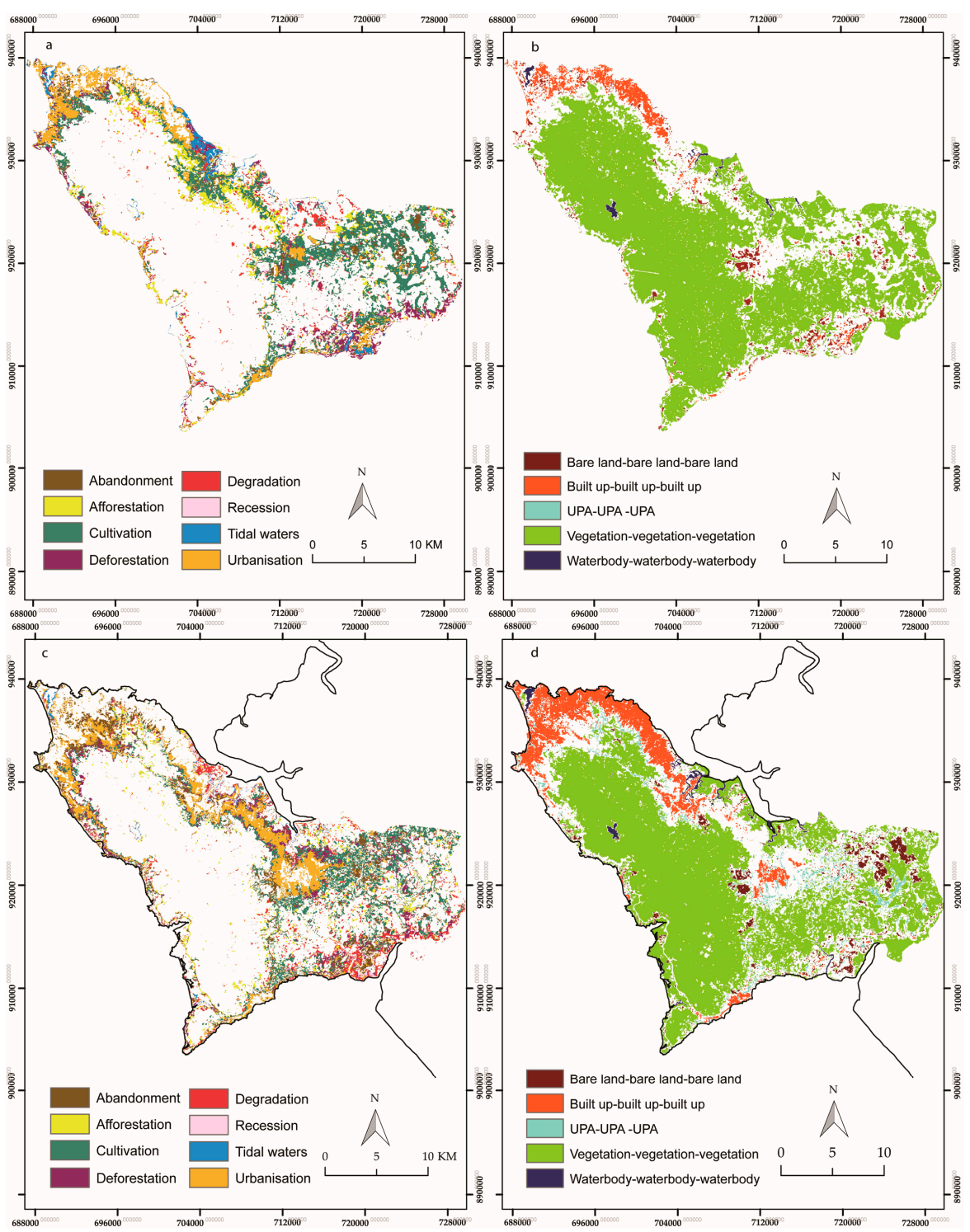

Figure 8. Land cover change trajectory maps: (a) Changed trajectory pixels 1976-2000; (b) Unchanged trajectory pixels 1976-2000; (c) Changed trajectory pixels 2003-2011; (d) Unchanged trajectory pixels 2003-2011. 
Table 5. Percentage areas of LCC trajectories before and during the war (1976-2000) and after the war (2003-2011). Note that all figures were rounded up to the nearest whole number. Italicised trajectories are those that could not be calculated for the first time period because agriculture was not identifiable in the 1976 image.

\begin{tabular}{|c|c|c|c|c|}
\hline Process & Description & Trajectories & $\begin{array}{l}\text { 1976-2000 } \\
\text { Area (ha) }\end{array}$ & $\begin{array}{l}\text { 2003-2011 } \\
\text { Area (ha) }\end{array}$ \\
\hline No change & $\begin{array}{l}\text { Land class that remained } \\
\text { unchanged (stability of a given } \\
\text { land class). }\end{array}$ & $\begin{aligned} \mathrm{B} & \rightarrow \mathrm{B} \rightarrow \mathrm{B} \\
\mathrm{Br} & \rightarrow \mathrm{Br} \rightarrow \mathrm{Br} \\
\mathrm{V} & \rightarrow \mathrm{V} \rightarrow \mathrm{V} \\
\mathrm{W} & \rightarrow \mathrm{W} \rightarrow \mathrm{W} \\
A & \rightarrow A \rightarrow A\end{aligned}$ & $\begin{array}{c}1912(2.8 \%) \\
1572(2.3 \%) \\
43,214(63.6 \%) \\
303(0.4 \%) \\
- \\
\end{array}$ & $\begin{array}{c}5795(8.5 \%) \\
1874(2.7 \%) \\
36,346(54.2 \% \\
577(0.8 \%) \\
1714(2.5 \%) \\
\end{array}$ \\
\hline Urbanisation & $\begin{array}{l}\text { Increase in built-up from other } \\
\text { land classes }\end{array}$ & $\begin{array}{c}\mathrm{Br} \rightarrow \mathrm{B} \rightarrow \mathrm{B}, \mathrm{Br} \rightarrow \mathrm{Br} \rightarrow \mathrm{B}, \mathrm{Br} \rightarrow \mathrm{V} \rightarrow \mathrm{B}, \mathrm{Br} \rightarrow \mathrm{W} \rightarrow \mathrm{B}, \mathrm{Br} \rightarrow \mathrm{A} \rightarrow \mathrm{B}, \mathrm{V} \rightarrow \mathrm{B} \rightarrow \mathrm{B}, \mathrm{V} \rightarrow \mathrm{Br} \rightarrow \mathrm{B}, \\
\mathrm{V} \rightarrow \mathrm{V} \rightarrow \mathrm{B}, \mathrm{V} \rightarrow \mathrm{W} \rightarrow \mathrm{B}, \mathrm{V} \rightarrow \mathrm{A} \rightarrow \mathrm{B}, \mathrm{W} \rightarrow \mathrm{B} \rightarrow \mathrm{B}, \mathrm{W} \rightarrow \mathrm{Br} \rightarrow \mathrm{B}, \mathrm{W} \rightarrow \mathrm{V} \rightarrow \mathrm{B}, \mathrm{W} \rightarrow \mathrm{W} \rightarrow \mathrm{B}, \\
\mathrm{W} \rightarrow \mathrm{A} \rightarrow \mathrm{B}, A \rightarrow B \rightarrow B, A \rightarrow B r \rightarrow B, A \rightarrow V \rightarrow B, A \rightarrow W \rightarrow B, A \rightarrow A \rightarrow B\end{array}$ & $3234(4.8 \%)$ & $4713(6.9 \%)$ \\
\hline Afforestation & $\begin{array}{l}\text { Re-establishment or } \\
\text { densification of woody } \\
\text { vegetation }\end{array}$ & $\begin{array}{c}\mathrm{Br} \rightarrow \mathrm{Br} \rightarrow \mathrm{V}, \mathrm{Br} \rightarrow \mathrm{V} \rightarrow \mathrm{V}, \mathrm{Br} \rightarrow \mathrm{W} \rightarrow \mathrm{V}, \mathrm{Br} \rightarrow \mathrm{A} \rightarrow \mathrm{V}, \mathrm{W} \rightarrow \mathrm{B} \rightarrow \mathrm{V}, \mathrm{W} \rightarrow \mathrm{Br} \rightarrow \mathrm{V}, \mathrm{W} \rightarrow \mathrm{V} \rightarrow \mathrm{V}, \\
\mathrm{W} \rightarrow \mathrm{W} \rightarrow \mathrm{V}, \mathrm{W} \rightarrow \mathrm{A} \rightarrow \mathrm{V}, A \rightarrow B \rightarrow V, A \rightarrow B r \rightarrow V, A \rightarrow V \rightarrow V, A \rightarrow W \rightarrow V, A \rightarrow A \rightarrow V\end{array}$ & $2238(3.3 \%)$ & $2217(3.2 \%)$ \\
\hline Degradation & $\begin{array}{l}\text { De-densification of woody } \\
\text { vegetation }\end{array}$ & $\mathrm{V} \rightarrow \mathrm{Br} \rightarrow \mathrm{V}, \mathrm{V} \rightarrow \mathrm{W} \rightarrow \mathrm{V}, \mathrm{V} \rightarrow \mathrm{A} \rightarrow \mathrm{V}$ & $1669(2.5 \%)$ & $2429(3.6 \%)$ \\
\hline Deforestation & Woody vegetation removal & $\mathrm{W} \rightarrow \mathrm{V} \rightarrow \mathrm{Br}, \mathrm{V} \rightarrow \mathrm{V} \rightarrow \mathrm{Br}, \mathrm{V} \rightarrow \mathrm{Br} \rightarrow \mathrm{Br}, \mathrm{Br} \rightarrow \mathrm{V} \rightarrow \mathrm{Br}, A \rightarrow V \rightarrow B r$ & $2010(3.0 \%)$ & $2261(3.3 \%)$ \\
\hline Recession & $\begin{array}{l}\text { Waterlogged areas that become } \\
\text { dry land }\end{array}$ & $\mathrm{V} \rightarrow \mathrm{W} \rightarrow \mathrm{Br}, \mathrm{Br} \rightarrow \mathrm{W} \rightarrow \mathrm{Br}, \mathrm{W} \rightarrow \mathrm{W} \rightarrow \mathrm{Br}, \mathrm{W} \rightarrow \mathrm{Br} \rightarrow \mathrm{Br}$ & $131(0.2 \%)$ & $131(0.2 \%)$ \\
\hline Abandonment & $\begin{array}{l}\text { Previously cultivated land area } \\
\text { or occupied by other land class } \\
\text { in the previous years but } \\
\text { became bare land in later years }\end{array}$ & $\begin{aligned} \mathrm{Br} \rightarrow \mathrm{A} \rightarrow \mathrm{Br}, \mathrm{V} \rightarrow \mathrm{B} \rightarrow \mathrm{Br}, \mathrm{V} \rightarrow \mathrm{A} \rightarrow \mathrm{Br}, \mathrm{W} \rightarrow \mathrm{B} \rightarrow \mathrm{Br}, \mathrm{W} \rightarrow \mathrm{A} \rightarrow \mathrm{Br}, A \rightarrow B \rightarrow B r, A \rightarrow B r \rightarrow B r \\
A \rightarrow A \rightarrow B r\end{aligned}$ & $1440(2.1 \%)$ & $3028(4.4 \%)$ \\
\hline Cultivation & $\begin{array}{l}\text { Area previously occupied by } \\
\text { other land classes but later used } \\
\text { for UPA }\end{array}$ & $\begin{aligned} \mathrm{Br} \rightarrow \mathrm{Br} \rightarrow \mathrm{A}, \mathrm{Br} \rightarrow \mathrm{V} \rightarrow \mathrm{A}, \mathrm{Br} \rightarrow \mathrm{W} \rightarrow \mathrm{A}, \mathrm{Br} \rightarrow \mathrm{A} \rightarrow \mathrm{A}, \mathrm{V} \rightarrow \mathrm{B} \rightarrow \mathrm{A}, \mathrm{V} \rightarrow \mathrm{Br} \rightarrow \mathrm{A}, \mathrm{V} \rightarrow \mathrm{V} \rightarrow \mathrm{A}, \\
\mathrm{V} \rightarrow \mathrm{W} \rightarrow \mathrm{A}, \mathrm{V} \rightarrow \mathrm{A} \rightarrow \mathrm{A}, \mathrm{W} \rightarrow \mathrm{B} \rightarrow \mathrm{A}, \mathrm{W} \rightarrow \mathrm{Br} \rightarrow \mathrm{A}, \mathrm{W} \rightarrow \mathrm{V} \rightarrow \mathrm{A}, \mathrm{W} \rightarrow \mathrm{W} \rightarrow \mathrm{A}, \mathrm{W} \rightarrow \mathrm{A} \rightarrow \mathrm{A}, \\
\quad A \rightarrow B \rightarrow A, A \rightarrow B r \rightarrow A, A \rightarrow V \rightarrow A, A \rightarrow W \rightarrow A\end{aligned}$ & $7806(11.5 \%)$ & $5540(8.1 \%)$ \\
\hline Tidal waters & $\begin{array}{l}\text { Occupancy of land with water } \\
\text { due to tidal rise }\end{array}$ & $\begin{array}{c}\mathrm{Br} \rightarrow \mathrm{Br} \rightarrow \mathrm{W}, \mathrm{Br} \rightarrow \mathrm{V} \rightarrow \mathrm{W}, \mathrm{Br} \rightarrow \mathrm{A} \rightarrow \mathrm{W}, \mathrm{V} \rightarrow \mathrm{B} \rightarrow \mathrm{W}, \mathrm{V} \rightarrow \mathrm{Br} \rightarrow \mathrm{W}, \mathrm{V} \rightarrow \mathrm{V} \rightarrow \mathrm{W}, \mathrm{V} \rightarrow \mathrm{A} \rightarrow \mathrm{W}, \\
\mathrm{B} \rightarrow \mathrm{W} \rightarrow \mathrm{W}, \mathrm{Br} \rightarrow \mathrm{W} \rightarrow \mathrm{W}, \mathrm{V} \rightarrow \mathrm{W} \rightarrow \mathrm{W}, \mathrm{W} \rightarrow \mathrm{B} \rightarrow \mathrm{W}, \mathrm{W} \rightarrow \mathrm{Br} \rightarrow \mathrm{W}, \mathrm{W} \rightarrow \mathrm{V} \rightarrow \mathrm{W}, \mathrm{W} \rightarrow \mathrm{A} \rightarrow \mathrm{W}, \\
A \rightarrow B \rightarrow W, A \rightarrow \mathrm{Br} \rightarrow \mathrm{W}, A \rightarrow V \rightarrow W, A \rightarrow W \rightarrow W, A \rightarrow A \rightarrow W\end{array}$ & $316(0.5 \%)$ & $73(0.1 \%)$ \\
\hline $\begin{array}{l}\text { Impossible } \\
\text { transitions }\end{array}$ & $\begin{array}{l}\text { Trajectories that are not } \\
\text { typically possible }\end{array}$ & $\begin{array}{c}\mathrm{B} \rightarrow \mathrm{B} \rightarrow \mathrm{W}, \mathrm{B} \rightarrow \mathrm{Br} \rightarrow \mathrm{B}, \mathrm{B} \rightarrow \mathrm{V} \rightarrow \mathrm{B}, \mathrm{B} \rightarrow \mathrm{W} \rightarrow \mathrm{B}, \mathrm{B} \rightarrow \mathrm{A} \rightarrow \mathrm{B}, \mathrm{B} \rightarrow \mathrm{B} \rightarrow \mathrm{V}, \mathrm{B} \rightarrow \mathrm{Br} \rightarrow \mathrm{V}, \mathrm{B} \rightarrow \mathrm{V} \rightarrow \mathrm{V}, \\
\mathrm{B} \rightarrow \mathrm{W} \rightarrow \mathrm{V}, \mathrm{B} \rightarrow \mathrm{A} \rightarrow \mathrm{V}, \mathrm{Br} \rightarrow \mathrm{B} \rightarrow \mathrm{V}, \mathrm{V} \rightarrow \mathrm{B} \rightarrow \mathrm{V}, \mathrm{B} \rightarrow \mathrm{V} \rightarrow \mathrm{Br}, \mathrm{B} \rightarrow \mathrm{W} \rightarrow \mathrm{Br}, \mathrm{B} \rightarrow \mathrm{B} \rightarrow \mathrm{Br}, \\
\mathrm{B} \rightarrow \mathrm{Br} \rightarrow \mathrm{Br}, \mathrm{B} \rightarrow \mathrm{A} \rightarrow \mathrm{Br}, \mathrm{Br} \rightarrow \mathrm{B} \rightarrow \mathrm{Br}, \mathrm{B} \rightarrow \mathrm{B} \rightarrow \mathrm{A}, \mathrm{V} \rightarrow \mathrm{B} \rightarrow \mathrm{A}, \mathrm{V} \rightarrow \mathrm{B} \rightarrow \mathrm{W}, \mathrm{B} \rightarrow \mathrm{Br} \rightarrow \mathrm{A}, \\
\mathrm{B} \rightarrow \mathrm{V} \rightarrow \mathrm{A}, \mathrm{B} \rightarrow \mathrm{W} \rightarrow \mathrm{A}, \mathrm{B} \rightarrow \mathrm{A} \rightarrow \mathrm{A}, \mathrm{Br} \rightarrow \mathrm{B} \rightarrow \mathrm{A}, \mathrm{B} \rightarrow \mathrm{Br} \rightarrow \mathrm{W}, \mathrm{B} \rightarrow \mathrm{V} \rightarrow \mathrm{W}, \mathrm{B} \rightarrow \mathrm{A} \rightarrow \mathrm{W}, \\
\quad \mathrm{Br} \rightarrow \mathrm{B} \rightarrow \mathrm{W}, \mathrm{W} \rightarrow \mathrm{B} \rightarrow \mathrm{W}, A \rightarrow \mathrm{B} \rightarrow \mathrm{A}\end{array}$ & $2070(3.0 \%)$ & $1678(2.5 \%)$ \\
\hline
\end{tabular}




\subsection{Fragmentation Metrics}

Figure 9 illustrates the pattern of landscape fragmentation over time (1986-2011). At the landscape scale, the computed metrics provide weak evidence of progressive landscape fragmentation over the whole study period and no evidence that fragmentation levels were markedly different in the post-war period compared with the overall trend. Across the study period, SHDI and SDI increased, while LPI and CONTAG decreased; all expected directions of change when fragmentation is occurring (Figure 9). Examination of the class-level fragmentation metrics (Figure 10) and the maps of land cover (Figure 5), however, provide more nuanced information than the landscape-level metrics, showing some evidence that aggregation processes are happening in addition to fragmentation processes. For example, PLAND for the built-up class increased throughout the post-war period. NumP for the built-up class, however, decreased indicating aggregation. This is clearly visible on the maps in Figure 5, where urban infill is occurring. Other class-level fragmentation metrics also support this contention, for example, the largest patch index (LPI) also increased for the built-up class.
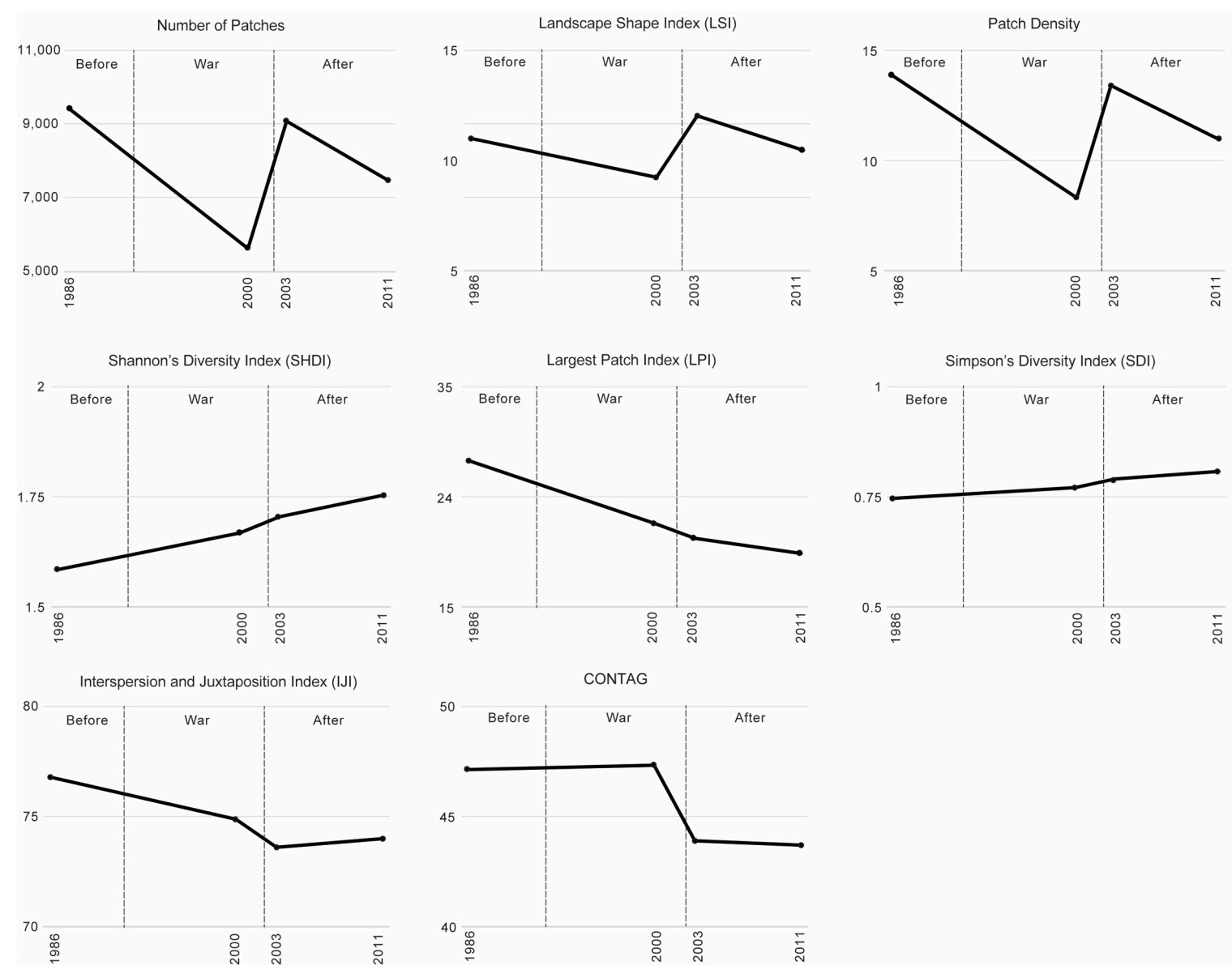

Figure 9. Landscape level fragmentation metrics.

So, if the built-up class is aggregating, what is causing the overall level of fragmentation to slightly increase, as shown by the landscape-scale metrics? This pattern is driven primarily by the bare land class, which has a fairly flat LPI, a slightly increased NumP, and a slightly increased LSI (Figure 10). LSI measures the configuration of patches - the density of edges, or in other words the degree to which classes are interspersed with each other. Therefore, when this measure is high (and bare land is among the highest of all the classes), it suggests fragmentation within the landscape. Indeed, inspection of the 2006 and 2011 land cover maps, corroborated with field visits, indicates many patches of bare land, particularly within the urban footprint and fringes. Other forest also provides some contribution to 
the landscape-level fragmentation. It is occupying a smaller percentage of the available land, and has a substantially lower largest patch index but a fairly flat LSI, suggesting its losses are occurring at the edges rather than the middle of existing areas of other forest.
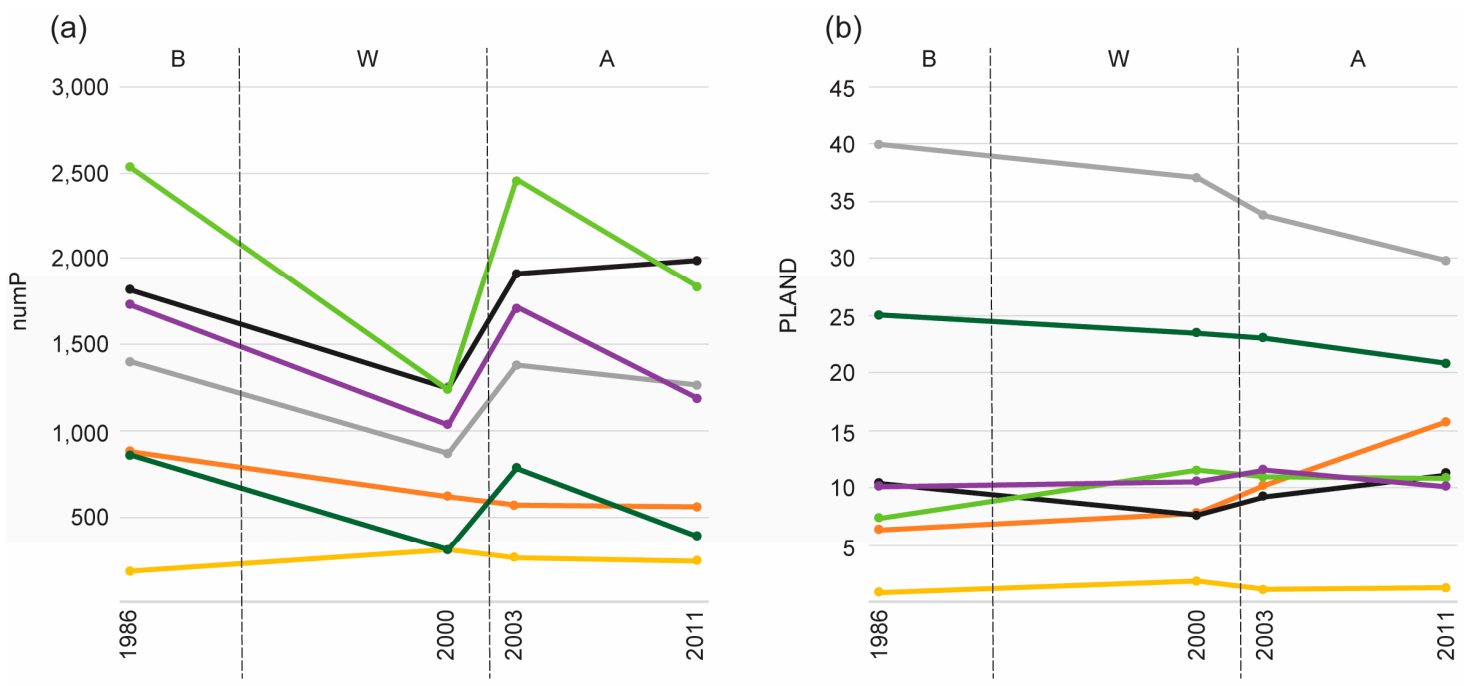

(c)
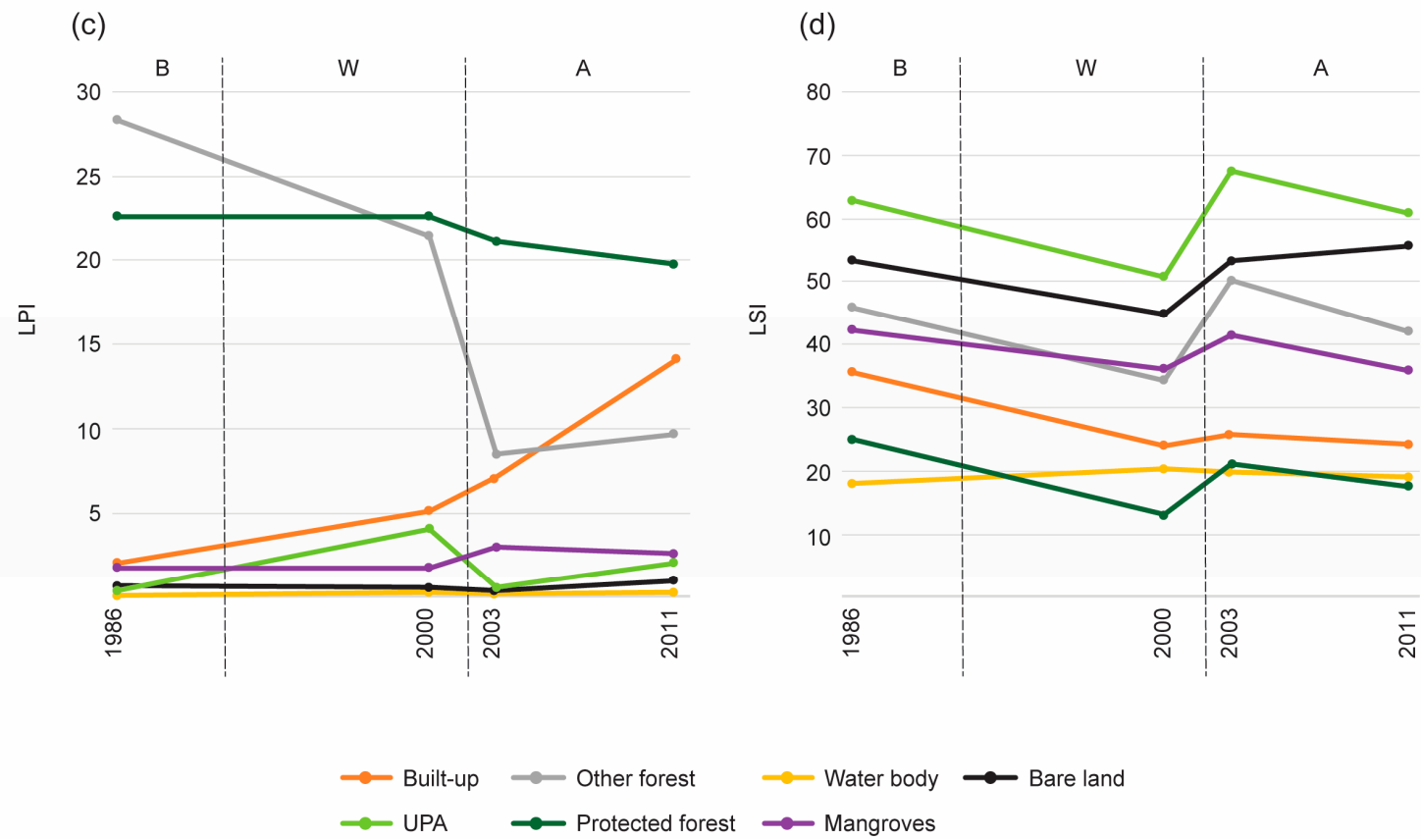

Figure 10. Land class-level fragmentation metrics: (a) number of parcels (numP); (b) percentage of landscape (PLAND); (c) largest patches index (LPI); (d) landscape shape index (LSI). B: before the war; $\mathrm{W}$ : during the war; A: after the war.

\section{Discussion}

The accelerated rural-urban migration, especially during the civil war and thereafter, has greatly contributed to the transformation of the WA's landscape. A study that strongly recognised the contribution of forced migration (i.e., internal displacement of the population) during Sierra Leone's civil war to WA's landscape change [5] stated that population expansion would not likely have significant impact on the spatial extent of urban areas. Wilson [5] argued that while in certain circumstances there would be recorded population growth, there was a high likelihood that people 
would tend to concentrate in existing built-up areas. An earlier study by Forkuor and Cofie [9] and Mansaray et al.'s [7] investigation seem to disagree with Wilson's argument: they suggest that forced migration and mass infrastructure development have not only expanded the city limits due to competing demands for land from different stakeholders and that UPA farmers lost their land to higher bidders. Our analysis agrees with Forkuor and Cofie [9] and Mansaray et al.'s [7] research in Sierra Leone, specifically and with previous research on the impact of civil wars/conflicts on LCC in other locations [2,6,17]. Our results suggest that the accelerated rural-urban migration that occurred during the war has shaped the region's landscape, which is somewhat more fragmented now compared with before the war. LCC and landscape fragmentation in the region is due to land cover conversion to built-up environments and over-exploitation of forest resources from livelihood initiatives, such as wood harvesting, agricultural activities, and charcoal burning. While Wilson [5] and Mansaray et al. [7] focused their investigations on metropolitan Freetown, we extended their work into adjacent areas in the WARDC.

We hypothesized that rural-urban migration and the reluctance of some IDPs who fled to the WA during the civil war to return to their rural homes would cause increased landscape fragmentation and a faster rate of LCC. We found weak evidence to support this hypothesis. However, our findings provide additional support for Li et al.'s [37] and Reddy et al.'s [63] argument that accelerated urbanisation in developing countries expedites forest conversion. Spatio-temporal trend analysis from 1976 to 2011 shows that the WA has a very dynamic landscape, with a decline in forest cover and an increase in built-up, bare land, and UPA land covers. The changes in the WA landscape, including the $241 \%$ urban expansion ( $2342.0 \mathrm{ha}), 47 \%$ growth in UPA ( 2322.0 ha) and $54 \%$ decline in forest ( $37 \%$ for other forest ( $3277.5 \mathrm{ha}$ ) and $17 \%$ for protected forest (625.7 ha)) can be explained in part by the increase in population described in Section 3 [26]. The net loss of forest cover, which appears to be minor in comparison to the rate of urban expansion, should not be ignored because since the declaration of peace in 2002, reconstruction and livelihood rebuilding efforts have taken centre stage in Sierra Leone. The increase in bare land and the decrease in forest covers is the outcome of deforestation driven by an increase in demand for fuel wood, charcoal and construction materials, and land for housing development and agricultural activities. As one of Sierra Leone's most urbanised regions, the dollarization of house rents has had substantial influence upon the swiftly rising increase in land prices [24]. The increase in land price influences the conversion of forest into bare land and bare land to built-up land through a process of illegal land possession described by Gbanie et al. [24] as land grabbing.

The increase in protected forest (25\%) between 1976 and 1986 and its continuous decline thereafter is slightly higher than Forkuor and Cofie's [9] estimates, which showed a growth of $18 \%$ between 1974 and 1986 for evergreen forest. Although Forkuor and Cofie [9] did not explain what constituted evergreen forest in their analysis, this class' spatial location coincides with areas covered by this research's protected forest class (Figure 5) and which we defined as reserved and protected forest areas (see Table 2). The observed differences can be partially explained by the somewhat different image dates, our up-sampling of pixels from $60 \mathrm{~m}$ to $30 \mathrm{~m}$ in the 1976 image, and perhaps differences in land cover classification accuracy. Like Wilson [5], this study demonstrated a steady nibbling away of the protected forest by other forest (Figure 5). This situation, known as 'edge influence,' is a result of deforestation at the urban-bush interface.

The observed expansion in UPA from 4940 to 7282 ha (1986-2011) can be explained by the IDPs and low-income urban dwellers with agricultural skills practicing UPA, both as a livelihood coping mechanism and to provide some degree of food security [5,51]. While UPA can be traced back to pre-independence Sierra Leone in the mountain villages of Gloucester and Leicester [50], it became widespread during the war, thus gaining policy attention after the war [26,51]. The increase in built-up of $241 \%$ between 1976 and 2011 led to a substantial loss in area of WA's natural ecosystems, such as woody vegetation cover, to infrastructure development. Land cover maps in Figure 5 clearly illustrate this pattern. Transition of woody vegetation to UPA was high during 2000-2003 and 2006-2011, and 
the transition of UPA to built-up remained consistent from 2000 through 2006 but increased between 2006 and 2011. The results also show that the principal sources of bare land were woody vegetation and UPA, and those of built-up were UPA and bare land. In addition to deforestation, abandonment of cultivated fields increased bare land.

These results agree with those of previous studies that have concluded that agricultural expansion, infrastructure development, and wood extraction are proximate drivers of LCC that are inextricably linked together $[1,64,65]$. This pattern has also been found by other studies that have examined the effect of civil war on the environment, like those in the South Sudan-Uganda border region and north Darfur, Sudan [2,17]. Our findings are consistent with other conflict-environment relationship research, which found deforestation through forest-based livelihood activities (fuel wood, charcoal) and informal settlement by IDP residents were major drivers of landscape change at the urban-bush interface [4,20].

The noticeable concentration of UPA activities at the urban fringes and in open spaces within the WA both during and after the war is also a pattern that is congruent with that found in earlier work $[9,66]$. There are several possible explanations for the observed pattern. The fear of being kidnapped by the fighting forces during the war, as was found in Marrupa and Mandimba districts, Mozambique, might be one cause [66]. In Sierra Leone, during the course of the conflict, the rebels used dense forest as a shield to avoid being noticed by flying helicopter gunships, thus venturing beyond the fringes of urban areas may have put local populations at greater risk. Another possible explanation for this trend in our study area is the easier access to forest edge areas of the WAPFoR, since they are at relatively low elevations compared to the inner forest, which is at higher elevation.

Overall, CONTAG, which measures the spatial aggregation of patches, decreased throughout the study period (Figure 9). Values near zero indicate maximal disaggregation and interspersion, i.e., fragmentation [60]. Although there was a general decline in CONTAG over the study period, the decline became more prominent between 2000 and 2003, a period that coincided with the start of the post-conflict reconstruction. The levelling off of CONTAG, between 2003 and 2011 supports the assertion that fragmented patches, such as the urban class, were aggregating. Moreover, the continuous and almost linear increases in Shannon's and Simpson's Diversity indices indicate landscape fragmentation. The trend further confirms that the WA landscape witnessed some level of fragmentation over the whole study period.

At the land class scale, the alternating increase and decrease in NumP over time for the UPA class illustrates the fusing of individual patches of a land cover class with each other. For instance, it could be inferred that a decline in NumP could represent the merging of either isolated agricultural fields or the replacement of such fields by the sprawling urban environment. Kabba and Li [45] showed a similar landscape fragmentation pattern in Wuhan, China that was indicative of urban structures (housing development and road network) replacing agricultural fields. The decline in NumP for UPA is expected, as one major problem with UPA activities in the WA is insecure land tenure [50,51]. In an insecure land tenure system, it is common for land title deed holders to eject UPA farmers who cultivate on rented urban land parcels for housing development. This perhaps explains the decline in UPA in 2011 (Figure 5).

The PLAND and LPI metrics for both forest classes reveal a substantial loss of the WA's natural habitat, especially in the last ten years of the study period. The dominance of built-up areas, represented by the increase in LPI and PLAND figures, is a result of the elimination of other land cover classes like UPA, waterbody, and bare land within the urban footprint. Such transitions lead to greater connectivity between isolated urban patches, aggregating and connecting them with other urban patches [45]. The decrease in the LPI and PLAND metrics for forest cover is not surprising because bare land and UPA increased at the expense of natural vegetation (Figure 8). Results from the two dominance indices (LPI and PLAND) at the class level are congruent with Dewan et al.'s [44] argument that a positive correlation exists between increased human activities and dominance indices. The fragmentation and aggregation indices also support earlier research, which hypothesised that an increase in fragmentation 
will happen in areas of human habitation because of uncontrolled exploitation of forest resources, especially in settlements triggered by war [11].

As argued in Section 2.2, increased landscape fragmentation reduces the aesthetic value and habitat quality of landscapes by distorting the structure of the patch size and shape [61]. Given such impacts, results from fragmentation analysis in the study area raise questions about the environmental implications of these findings, which is the focus of the next section.

\section{Environmental Implications of Findings}

The documented landscape change presented here, especially after the war, is not surprising given that reconstruction and livelihood recovery efforts are major challenges of post-conflict societies $[24,26]$. This is because these processes require the use of natural resources, especially for agriculture-based economies like Sierra Leone's. Yet, these changes may have many negative environmental consequences both in the short and long term. Although it might seem to be a minor issue in the context of civil war and post-conflict rebuilding efforts, the landscape changes we observed from historical land cover change analysis have not only changed the aesthetic and touristic characteristics of the WA landscape but increased the likelihood of environmental hazards including landslides, erosion, and flooding. The flooding on 15 September 2015 and the landslide and flooding that occurred on 14 August 2017 are evidence of the negative effects of environmental change in the WA's landscape [67]. Unlike the 2015 Freetown flood event, which caused minimal damage but killed at least 12 people, the physical damage from the 2017 landslide and flooding has been substantial; estimated to be USD 30 million [68]. A rapid damage and loss assessment of the August 2017 flooding by The World Bank [68] linked the $6 \mathrm{~km}$-long landslide at Mount Sugar Loaf in Regent Village, WARDC to the unplanned urban sprawl into the mountain ranges.

In addition to the impacts from flooding and landslides, growth in built-up environments at the expense of cultivable land has the potential to compromise vegetable production efforts in the mountain villages of Regent, Leicester and Gloucester. As these villages are the primary source of fresh vegetables in Freetown, this may lead to negative health impacts among Freetown residents. The anticipated reduction in food production efforts can be attributed to the competing demands for land between urban development and UPA activities, as already highlighted by other scholars $[26,50]$.

Continued landscape change also has ecological implications. Apart from being home to the only chimpanzee sanctuary in the country, WAPFoR is home to 316 bird species, with the Green-tailed Bristlebill and White-breasted Rock fowl (Picathartes Gymnocephalus) classed as endangered species. Additionally, of the 200-plant species in the WA forest, 74 of them and one genus are endemic. Since fragmentation reduces connectivity in a landscape by disaggregating the land cover, current landscape changes will further endanger already endangered flora and fauna. This means animals that are often illegally harvested for bush meat, including the Red Colobus Monkeys, Black-and-White Colobus Monkeys, Sooty Mangabeys and Diana Monkeys, Leopards, Jentink's Duikers, Black Duikers and Maxwell Duikers are under threat. Moreover, proximity of human populations to forest edges is likely to lead to increased fuel wood extraction and bush meat harvesting, putting further pressure on threatened species.

\section{Conclusions}

Our research was designed to monitor the rate of LCC, trajectory trends, and the extent of landscape fragmentation in the WA of Sierra Leone using satellite images from 1976 to 2011. Our investigations showed that Sierra Leone's conflict in the 1990's triggered large changes in the WA's landscape, exemplified by the trajectory trends and fragmentation metrics, changes in the annual LCC statistics, and land cover transition patterns. More than $30 \%$ of pixels underwent at least one land cover transition during the study period. Our findings from the landscape fragmentation and LCC trajectory analysis in Section 5 provided some evidence to support the hypothesis that rural-urban migration, including the 'staying on' of IDPs at the conflict's end led to increased landscape 
fragmentation and accelerated LCC trajectories. An important finding to emerge from this research is that fragmentation increased in conjunction with increased built-up area $(+241 \%)$ and declining forest cover $(-54 \%)$. An implication of the competing demands for land from UPA farmers and for infrastructure development is the possibility of a decline in urban food production efforts, an activity that made the WA food secure, particularly during the war.

The analysis of LCC trajectories and landscape fragmentation both at the class and landscape levels undertaken here has extended our understanding of LULCC in the WA [5,7,9] and that of previous research on the impact of conflict on the environment [2,11-15]. Our research provides the first detailed assessment of the extent and magnitude of landscape fragmentation and trajectory trends in the WA, findings that are useful to conservation planning and management efforts for WAPFoR. The evidence of a continued nibbling away of protected forest provides compelling evidence that Sierra Leone's current land use planning interventions have proven to be ineffective in protecting the WAPFoR. The ineffectiveness of current land use policy and planning interventions could be linked to several issues of forest and resource governance in the country including: (1) fragmentation of land resource management responsibilities among several ministries, department and agencies (Ministry of Lands Country Planning and the Environment, Environmental Protection Agency, Ministry of Agriculture Forestry and Food Security and Ministry of Mines and Mineral Resources); (2) the lack of a comprehensive land use plan; and (3) inadequate policies that address land resource management issues at regional levels, given that two different land tenure arrangements govern land administration in the country.

An interesting extension of this study would be a comparative investigation into landscape fragmentation and LCC trajectories trends in an environment that has not experienced conflict but has recorded increased population from rural-urban migration using comparable data sets. Analysis of trajectory trends at the core and periphery levels of the study area could perhaps provide a different perspective. This would help to identify whether conflict indeed plays a unique role in landscape change, or whether the increase in population remains the main driving force. Additionally, further investigations that explore the relationships between landscape change metrics and socio-economic and demographic variables to further enhance our understanding of WA's landscape change are strongly recommended. These variables might include but are not limited to, population growth, per-capita GDP, and gross agricultural output. Such studies will help to identify the role of socio-economic processes, if any, in contributing to increased landscape fragmentation or aggregation.

Acknowledgments: The research on which this paper is based was jointly funded by the UNSW Tuition Fee Scholarship and Faculty Stipend under the University College Postgraduate Research Scholarship (UCPRS) scheme. The authors thank Matt Beaty for providing thought-provoking comments and meaningful suggestions that helped improved the manuscript. We wish to thank Jeff Thompson for his help in the layout of the figures and Julie Kesby (Research Officer, UNSW Canberra) for her editorial advice and help with the EndNote library.

Author Contributions: Solomon Peter Gbanie developed the research concepts and analysed the data and wrote the manuscript, Amy L. Griffin and Alec Thornton supervised the research process, ensured that all research ethics were adhered to and data corrected, and helped in designing and writing the manuscript.

Conflicts of Interest: There is no conflict of interest.

\section{References}

1. Geist, H.J.; Lambin, E.F. Proximate causes and underlying driving forces of tropical deforestation. BioScience 2002, 52, 143-150. [CrossRef]

2. Gorsevski, V.; Kasischke, E.; Dempewolf, J.; Loboda, T.; Grossmann, F. Analysis of the Impacts of armed conflict on the Eastern Afromontane forest region on the South Sudan-Uganda border using multitemporal Landsat imagery. Remote Sens. Environ. 2012, 118, 10-20. [CrossRef]

3. Tejaswi, G. Manual on Deforestation, Degradation and Fragmentation Using Remote Sensing and GIS; MAR-SFM Working Paper 5; Food and Agriculture Organization of the United Nations: Rome, Italy, 2007.

4. Dudley, J.P.; Ginsberg, J.R.; Plumptre, A.J.; Hart, J.A.; Campos, L.C. Effects of war and civil strife on wildlife and wildlife habitats. Conserv. Biol. 2002, 16, 319-329. [CrossRef] 
5. Wilson, C. Spectral analysis of civil conflict-induced forced migration on land-use/land-cover change: The case of a primate and lower-ranked cities in Sierra Leone. Int. J. Remote Sens. 2014, 35, 1094-1125. [CrossRef]

6. Witmer, F.D.W. Detecting war-induced abandoned agricultural land in northeast Bosnia using multispectral, multitemporal Landsat TM imagery. Int. J. Remote Sens. 2008, 29, 3805-3831. [CrossRef]

7. Mansaray, L.R.; Huang, J.; Kamara, A.A. Mapping deforestation and urban expansion in Freetown, Sierra Leone, from pre- to post-war economic recovery. Environ. Monit. Assess. 2016. [CrossRef] [PubMed]

8. Baumann, M.; Radeloff, V.C.; Avedian, V.; Kuemmerle, T. Land-use change in the Caucasus during and after the Nagorno-Karabakh conflict. Reg. Environ. Chang. 2015, 15, 1703-1716. [CrossRef]

9. Forkuor, G.; Cofie, O. Dynamics of land-use and land-cover change in Freetown, Sierra Leone and its effects on urban and peri-urban agriculture-A remote sensing approach. Int. J. Remote Sens. 2011, 32, 1017-1037. [CrossRef]

10. Hoffman, D. The Disappeared: Images of the environment at Freetown's urban margins. Vis. Stud. 2007, 22, 104-119. [CrossRef]

11. Stevens, K.; Campbell, L.; Urquhart, G.; Kramer, D.; Qi, J. Examining complexities of forest cover change during armed conflict on Nicaragua's Atlantic Coast. Biodivers. Conserv. 2011, 20, 2597-2613. [CrossRef]

12. Ordway, E.M. Political shifts and changing forests: Effects of armed conflict on forest conservation in Rwanda. Glob. Ecol. Conserv. 2015, 3, 448-460. [CrossRef]

13. Brady, L.M. Life in the DMZ: Turning a diplomatic failure into an environmental success. Dipl. Hist. 2008, 32, 585-611. [CrossRef]

14. McNeely, J.A. Conserving forest biodiversity in times of violent conflict. Oryx 2003, 37, 142-152. [CrossRef]

15. McNeely, J.A. Biodiversity, war and tropical forests. J. Sustain. For. 2003, 16, 1-20. [CrossRef]

16. United Nations Environment Programme (UNDP). Sudan Post-Conflict Environmental Assessment; UNDP: Nairobi, Kenya, 2007.

17. Hagenlocher, M.; Lang, S.; Tiede, D. Integrated assessment of the environmental impact of an IDP camp in Sudan based on very high resolution multi-temporal satellite imagery. Remote Sens. Environ. 2012, 126, 27-38. [CrossRef]

18. Brown, O.; Hauptfleisch, M.; Jallow, H.; Tarr, P. Environmental assessment as a tool for peacebuilding and development: Initial lessons from capacity building in Sierra Leone. In Assessing and Restoring Natural Resources in Post-Conflict Peacebuilding; Jensen, D., Logergan, S., Eds.; Routledge: London, UK, 2012.

19. Gorsevski, V.; Geores, M.; Kasischke, E. Human dimensions of land use and land cover change related to civil unrest in the Imatong Mountains of South Sudan. Appl. Geogr. 2013, 38, 64-75. [CrossRef]

20. Nackoney, J.; Molinario, G.; Potapov, P.; Turubanova, S.; Hansen, M.C.; Furuichi, T. Impacts of civil conflict on primary forest habitat in northern Democratic Republic of the Congo, 1990-2010. Biol. Conserv. 2014, 170, 321-328. [CrossRef]

21. Unruh, J.D. Land tenure and legal pluralism in the peace process. Peace Chang. 2003, 28, 352-377. [CrossRef]

22. Mitchell, M.G.; Bennett, E.M.; Gonzalez, A. Forest fragments modulate the provision of multiple ecosystem services. J. Appl. Ecol. 2014, 51, 909-918. [CrossRef]

23. Unruh, J.D. Toward Sustainable Livelihoods after War: Reconstituting Rural Land Tenure Systems. Nat. Res. Forum 2008, 32, 103-115. [CrossRef]

24. Gbanie, S.P.; Thornton, A.; Griffin, A.L. The Diamond of Western Area Is Land': Narratives of Land Use and Land Cover Change in Post-Conflict Sierra Leone. Australas. Rev. Afr. Stud. 2015, 32, 51-73.

25. Gbanie, S.P. Understanding Land Use and Land Cover Change in Post-War Sierra Leone: A Socio-Geospatial Approach. Ph.D. Thesis, University of New South Wales, Sydney, Australia, 2015.

26. Lynch, K.; Maconachie, R.; Binns, T.; Tengbe, P.; Bangura, K. Meeting the urban challenge? Urban agriculture and food security in post-conflict Freetown, Sierra Leone. Appl. Geogr. 2013, 36, 31-39. [CrossRef]

27. Biodiversity Analysis and Technical Support Team. 118/119 Biodiversity and Tropical Forest Assessment for Sierra Leone, EPIQ IQC: EPP-I-00-03-00014-00, Task Order 02, Prepared by the Biodiversity Analysis and Technical Support Team for Review by the United States Agency for International Development; USAID: Washington, DC, USA, 2007.

28. Glew, L.; Hudson, M. Gorillas in the midst: The impact of armed conflict on the conservation of protected areas in sub-Saharan Africa. Oryx 2007, 41, 140-150. [CrossRef]

29. Kanyamibwa, S. Impact of war on conservation: Rwandan environment and wildlife in agony. Biodivers. Conserv. 1998, 7, 1399-1406. [CrossRef] 
30. Coppin, P.; Jonckheere, I.; Nackaerts, K.; Muys, B.; Lambin, E.F. Review Article: Digital change detection methods in ecosystem monitoring: A review. Int. J. Remote Sens. 2004, 25, 1565-1596. [CrossRef]

31. Zhou, Q.; Li, B.; Kurban, A. Spatial pattern analysis of land cover change trajectories in Tarim Basin, northwest China. Int. J. Remote Sens. 2008, 29, 5495-5509. [CrossRef]

32. Liu, D.; Cai, S. A spatial-temporal modeling approach to reconstructing land-cover change trajectories from multi-temporal satellite imagery. Ann. Assoc. Am. Geogr. 2012, 102, 1329-1347. [CrossRef]

33. Zhou, Q.; Sun, B. Spatial pattern of farmland change trajectories in arid zone of China. Proc. SPIE 2008, 7285. [CrossRef]

34. Davis, C.R.; Hansen, A.J. Trajectories in land use change around US National Parks and challenges and opportunities for management. Ecol. Appl. 2011, 21, 3299-3316. [CrossRef]

35. Ruslan, R. Application of GIS and landscape metrics in monitoring urban land use change. In Urban Ecosystem Studies in Malaysia: A Study of Change; Hashim, N.M., Rainis, R., Eds.; Universal Publisher: Boca Raton, FL, USA, 2003; pp. 267-278.

36. Mertens, B.; Lambin, E.F. Land-cover-change trajectories in southern Cameroon. Ann. Assoc. Am. Geogr. 2000, 90, 467-494. [CrossRef]

37. Li, M.; Mao, L.; Zhou, C.; Vogelmann, J.E.; Zhu, Z. Comparing forest fragmentation and its drivers in China and the USA with Globcover v2. 2. J. Environ. Manag. 2010, 91, 2572-2580. [CrossRef] [PubMed]

38. Liu, Y.; Feng, Y.; Zhao, Z.; Zhang, Q.; Su, S. Socioeconomic drivers of forest loss and fragmentation: A comparison between different land use planning schemes and policy implications. Land Use Policy 2016, 54, 58-68. [CrossRef]

39. López-Barrera, F.; Manson, R.H.; Landgrave, R. Identifying deforestation attractors and patterns of fragmentation for seasonally dry tropical forest in central Veracruz, Mexico. Land Use Policy 2014, 41, 274-283. [CrossRef]

40. Carvalho, F.M.; De Marco, P.; Ferreira, L.G. The Cerrado into-pieces: Habitat fragmentation as a function of landscape use in the savannas of central Brazil. Biol. Conserv. 2009, 142, 1392-1403. [CrossRef]

41. Muriuki, G.; Seabrook, L.; McAlpine, C.; Jacobson, C.; Price, B.; Baxter, G. Land cover change under unplanned human settlements: A study of the Chyulu Hills squatters, Kenya. Landsc. Urban Plan. 2011, 99, 154-165. [CrossRef]

42. Fahrig, L. Effects of habitat fragmentation on biodiversity. Annu. Rev. Ecol. Evol. Syst. 2003, 487-515. [CrossRef]

43. Jaeger, J.A. Landscape division, splitting index and effective mesh size: New measures of landscape fragmentation. Landsc. Ecol. 2000, 15, 115-130. [CrossRef]

44. Dewan, A.M.; Yamaguchi, Y.; Rahman, M.Z. Dynamics of land use/cover changes and the analysis of landscape fragmentation in Dhaka Metropolitan, Bangladesh. GeoJournal 2012, 77, 315-330. [CrossRef]

45. Kabba, V.T.S.; Li, J. Analysis of land use and land cover changes and their ecological implications in Wuhan, China. J. Geogr. Geol. 2011, 3, 104-118. [CrossRef]

46. Xiaofeng, D.; Lichen, L.; Jianhua, W.; Jin, S.; Jinghu, P. Analysis of the landscape change at River Basin scale based on SPOT and TM fusion remote sensing images: A case study of the Weigou River Basin on the Chinese Loess Plateau. Int. J. Earth Sci. 2009, 98, 651-664. [CrossRef]

47. Fava, F.; Pulighe, G.; Monteiro, A. Mapping changes in land cover composition and pattern for comparing mediterranean rangeland restoration alternatives. Land Degrad. Dev. 2016, 27, 671-681. [CrossRef]

48. Tarawali, P. Diagnostic Analysis of Climate Change and Disaster Management in Relation to the PRSP III in Sierra Leone; United Nations Development Programme-Sierra Leone: Freetown, Sierra Leone, 2012.

49. Statistics Sierra Leone. 2015 Population and Housing Census: Summary of Final Results. Planning a Better Future; Statistics Sierra Leone: Freetown, Sierra Leone, 2016.

50. Maconachie, R.; Binns, T.; Tengbe, P. Urban farming associations, youth and food security in post-war Freetown, Sierra Leone. Cities 2012, 29, 192-200. [CrossRef]

51. Thornton, A.; Momoh, J.; Tengbe, P. Institutional capacity building for urban agriculture research using participatory GIS in post-conflict context: A case study of Sierra Leone. Aust. Rev. Afr. Stud. 2012, 33, $165-176$.

52. United States Geological Survey. USGS Global Visualization Viewer. 2001. Available online: https://glovis. usgs.gov (accessed on 19 January 2018). 
53. Lu, D.; Mausel, P.; Brondízio, E.; Moran, E. Assessment of atmospheric correction methods for Landsat TM data applicable to Amazon basin LBA research. Int. J. Remote Sens. 2002, 23, 2651-2671. [CrossRef]

54. Chander, G. Processsing need for sensor calibration. In Remote Sensing of Land Use and Land Cover: Principles and Application; Giri, C.P., Ed.; CRC Press: Boca Raton, FL, USA; London, UK; New York, NY, USA, 2012; pp. 113-126.

55. Anderson, J.R. A Land Use and Land Cover Classification System for Use with Remote Sensor Data; US Government Printing Office: Washington, DC, USA, 1976; Volume 964.

56. United Nations Educational, Scientific, and Cultural Organization (UNESCO). Western Area Peninsula National Park. 2012. Available online: http://whc.unesco.org/en/tentativelists/5741/ (accessed on 19 January 2018).

57. DiGirolamo, P.A. A Comparison of Change Detection Methods in an Urban Environment Using LANDSAT TM and ETM+ Satellite Imagery: A Multi-Temporal, Multi-Spectral Analysis of Gwinnett County, GA 1991-2000; Georgia State University: Atlanta, GA, USA, 2006.

58. Lu, D.; Mausel, P.; Brondizio, E.; Moran, E. Change detection techniques. Int. J. Remote Sens. 2004, 25, 2365-2401. [CrossRef]

59. Puyravaud, J.-P. Standardizing the calculation of annual rate of deforestation. For. Ecol. Manag. 2003, 177, 593-596. [CrossRef]

60. McGarigal, K.; Cushman, S.A.; Ene, E. FRAGSTAT v4 Spatial Pattern Analysis Program for Categorical and Continuous Maps. Computer Software Program Produced by the Authors at the University of Massachusetts. 2012. Available online: http:/ / www.umass.edu/landeco/research/fragstats/fragstats.html (accessed on 9 January 2018).

61. Riitters, K.H.; O'neill, R.; Hunsaker, C.; Wickham, J.D.; Yankee, D.; Timmins, S.; Jones, K.; Jackson, B. A factor analysis of landscape pattern and structure metrics. Landsc. Ecol. 1995, 10, 23-39. [CrossRef]

62. Shrestha, M.K.; York, A.M.; Boone, C.G.; Zhang, S. Land fragmentation due to rapid urbanization in the Phoenix Metropolitan Area: Analyzing the spatiotemporal patterns and drivers. Appl. Geogr. 2012, 32, 522-531. [CrossRef]

63. Reddy, S.C.; Sreelekshmi, S.; Jha, C.S.; Dadhwal, V.K. National assessment of forest fragmentation in India: Landscape indices as measures of the effects of fragmentation and forest cover change. Ecol. Eng. 2013, 60, 453-464. [CrossRef]

64. Braimoh, A.K. Agricultural land-use change during economic reforms in Ghana. Land Use Policy 2009, 26, 763-771. [CrossRef]

65. Griscom, H.R.; Miller, S.N.; Gyedu-Ababio, T.; Sivanpillai, R. Mapping land cover change of the Luvuvhu catchment, South Africa for environmental modelling. GeoJournal 2009, 75, 163-173. [CrossRef]

66. Temudo, M.P.; Silva, J.M.N. Agriculture and forest cover changes in post-war Mozambique. J. Land Use Sci. 2011, 7, 1-18. [CrossRef]

67. United Nations Institute for Training and Research Preliminary Landslide Inventory of Freetown, Sierra Leone 18 August 2017. Available online: http://www.unitar.org/unosat/node/44/2646?utm_source= unosat-unitar\&utm_medium=rss\&utm_campaign=maps (accessed on 7 September 2017).

68. The World Bank. Sierra Leone Rapid Damage and Loss Assessment of August 14th, 2017_Landslides and Floods in the Western Area; The World Bank: Washington, DC, USA, 2017.

(C) 2018 by the authors. Licensee MDPI, Basel, Switzerland. This article is an open access article distributed under the terms and conditions of the Creative Commons Attribution (CC BY) license (http:/ / creativecommons.org/licenses/by/4.0/). 